\title{
DEFLECTION AND STRESS ANALYSIS OF THE YANKEE CORE SUPPORT STRUCTURE
}

By

Gim H. Eng

September 22, 1958

Atomic Power Department

Westinghouse Electric Corporation

Pittsburgh, Pennsylvania

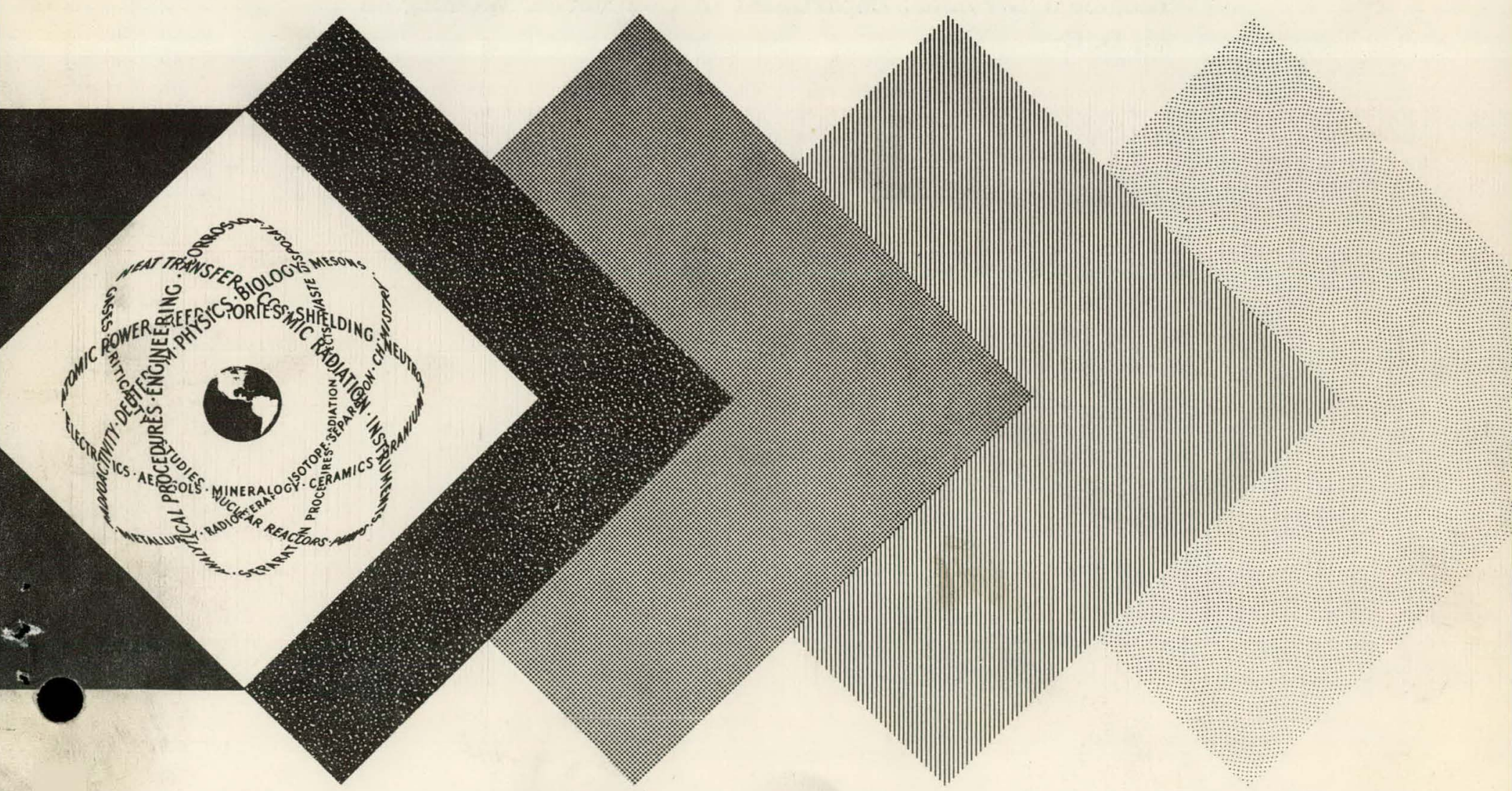




\section{DISCLAIMER}

This report was prepared as an account of work sponsored by an agency of the United States Government. Neither the United States Government nor any agency Thereof, nor any of their employees, makes any warranty, express or implied, or assumes any legal liability or responsibility for the accuracy, completeness, or usefulness of any information, apparatus, product, or process disclosed, or represents that its use would not infringe privately owned rights. Reference herein to any specific commercial product, process, or service by trade name, trademark, manufacturer, or otherwise does not necessarily constitute or imply its endorsement, recommendation, or favoring by the United States Government or any agency thereof. The views and opinions of authors expressed herein do not necessarily state or reflect those of the United States Government or any agency thereof. 


\section{DISCLAIMER}

Portions of this document may be illegible in electronic image products. Images are produced from the best available original document. 


\section{LEGAL NOTICE}

This report was prepared as an account of Government sponsored work. Neither the United States, nor the Commission, nor any person acting on behalf of the Commission:

A. Makes any warranty or representation, express or implied, with respect to the accuracy, completeness, or usefulness of the information contained in this report, or that the use of any information, apparatus, method, or process disclosed in this report may not infringe privately owned rights; or

B. Assumes any liabilities with respect to the use of, or for damages resulting from the use of any information, apparatus, method, or process disclosed in this report.

As used in the above, "person acting on behalf of the Commission" includes any employee or contractor of the Commission to the extent that such employee or contractor prepares, handles or distributes, or provides access to, any information pursuant to his employment or contract with the Commission.

This report has been reproduced directly from the best available copy.

Printed in USA. Price $\$ 1.50$. Available from the Office of Technical Services, Department of Commerce, Washington 25, D. C.

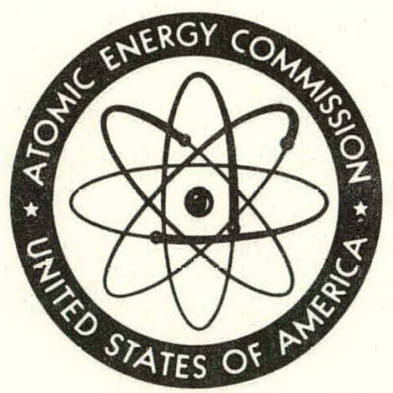




\section{PAGES 1 to 2 WERE INTENTIONALLY LEFT BLANK}


Yankee Atomic Electric Company

Research And Development Program

DEFLECTION AND STRESS ANALYSIS OF THE YANKEE

CORE SUPPORT STRUCTURE

by

Gim H. Eng

Reactor Engineering Department

For The Yankee Atomic Electric Company

Under Research and Development Subcontraot

No. 1 of USAEC-YAEC Contract AT(30-3)-222

September 22, 1958

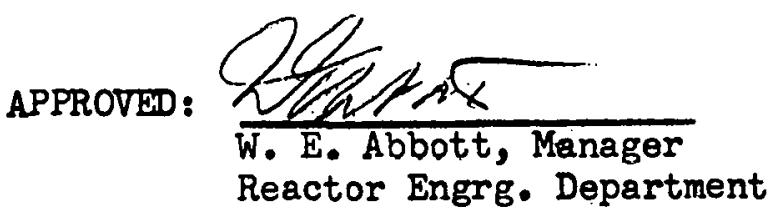

Westinghouse

CLECTAIC CORPORARION

ATOMIC POWER DEPARTMENT

P.o. Box 080

ATTEDUROH 30, PA. 
THIS PAGE

\section{WAS INTENTIONALLY \\ LEFT BLANK}


Page No.

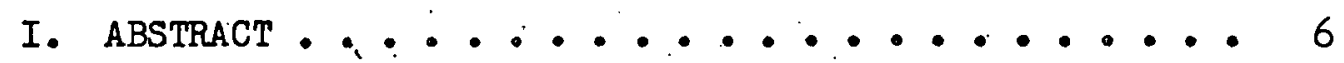

II. INTRODUCTION ... . . ......... 7

III. SUMMARY AND CONCLUSIONS. . . . . . . . . . 8

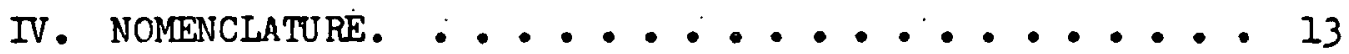

V. THEORETICAL APPROACHES TO THE CORE SUPPORT STRUCTURE ANALYSIS, ........... .......... 14

A. Perforated Plate ... . ....... 14

B. Sandwich Type Structure. . . . . . . . 14

C. Rational Method of Theoretical Analysis of the

Problem.............. 15

IV. EXPERIMENTS ON MODELS. . . . . . . . . 17

A. Similarity of Model and Reference Design. . . . 17

B. Test Specimens. . . . . . . . . 20

C. Test Apparatus. ........... $25^{\circ}$

D. Test Procedure .............. 32

E. Test Results ............ 33

VII, BIBLIOGRAPHY . . . . . . . . . . . 52 


\section{ABSTRACT}

The deflection and stresses of a model of the Yankee lower core support structure, consisting of two circular perforated plates joined together by a circular reinforcing rib and 76 cylindrical spacers, were obtained experimentally. The relationships between the tests on the model and reference design were determined by an application of dimensional analysis.

Experimental investigations are described in which various design parameters were determined and the structural rigidity of the assembly was nhtainer. A rational method of oomi-thcorctical analysis of the problem is suggested based on Reissner's small deflection theory which takes into account the effect of transverse shear and normal 'stress deformation. 
II. INTRODUCTION

The Yankee upper and lower core support structures are rigid sandwichtype assemblies consisting of two circular perforated plates joined together by a circular reinforcing $\mathrm{rib}$ and 76 inserted cylindrical spacers. The plates are perforated with circular holes in a square pitch for the coolant inlet and discharge nozzles of the individual fuel assemblies. In addition there are 25 small water holes and 32 cross-shaped slots for the cruciform control rods.

Figure 1 shows the model hole configuration and dimensions in one quarter scale. Figures 2 and 3 show an oblique and bottom view, respectively, of the core support structure model. The reference design. structure will be fabricated entirely of AISI 304 stainless steel to minimize corrosion problems, and is designed to employ thin metal sections for each component and to provide access for coolant within the structure to minimize thermal stresses resulting from gamma attenuation..

The individual fuel assemblies are held vertically in the reactor core between the upper and lower core support structures. The purposes of the lower core support structure are twofold:

1. To support the total weight of the fuel assemblies and maintain their orientation.

2. To support and secure the position of the control rod extension shrouds, and to guide the traveling of the control rods.

The purposes of the upper core support structure are:

1. To absorb the impact of the control rods during fast insertion or scramming.

2. To maintain the fuel assemblies in position and to guide the traveling of the control rods.

In view of the load-carrying requirements of the core support structure, and of the alignment required to produce reliable control-rod action in the reactor under all operating and emergency conditions, it is essential that the design of the structure be sound and adequate. Therefore, the deflections and stresses must be determined accurately.

A rational analysis of the behavior of the core support structure under concentric uniform loads is possible if the flexural and shear rigidities of the structure are known. However, due to the complex geometric shape and loading, a mathematical analysis of the problem would produce uncertain results and it is considered necessary to check the results on scaled models. Experiments on various models were conducted to obtain both the specific 
information required for this analysis and other optimum design parameters. By an application of dimensional analysis, the relationship between the model and the prototype was made to be in a predetermined ratio.

The upper core support structure is similar to the lower core support structure. Their hole configuration and dimensions are fixed by the geometry of the reactor core. Since the upper outer diameter and support loading are smaller, only the lower core support structure is considered in this report.

\section{SUMMARY AND CONCIUSIONS}

As a result of this model study the following design parameters of the Yankee lower core support structure are recommended:

1. Overall height: 8 inches

2. Top Plate, O.D.: 91 inches Thickness: $1-1 / 4$ inches

3. Bottom Plate, O.D.: $95-1 / 2$ inches Thickness: $1-1 / 2$ inches

4. Inserted Cylindrical Spacers, Thickness: $1 / 2$ inch .

5. Circular reinforcing rib,'Thickness: 1 inch

The maximum deflection on the lower surface of the core support structure is predicted as $0.0365^{\prime \prime}$. The maximum tensile stress is approximately 3600 psi and occurs on one side of the circular holes in the bottom support plate at the outer region.

The maximum slope of the bottom surface of the core support structure is calculated from the deflection curve, to be $1.504 \times 10-3$ in/in, which gives a fuel assembly a maximum horizontal movement of $0.153^{\prime \prime}$ at the upper end of the fuel assembly near the upper core support structure.

Tests in the hydraulic loop indicated that the size of the coolant water flow holes in the lower core support structure had a larger effect on the flow distribution in the core than did the internal geometry of the reactor core. It was recommended that the diameter of one water hole located at the center and four holes located $90^{\circ}$ apart at a 10.83 inch radial distance from the center be increased from 1.625 to 3.0 inches. Model tests indicated that this modification increased the deflection of the core structure by approximately 10\%. The maximum deflection and slope of the modified reference design are predicted to be 0.0415 inch and $1.71 \times 10-3$ in/in respectively. Although the stresses at the central region of core support structure show a slight increase, the maximum tensile stress remains the same and is located at the same region. 
The experimental deflections and stresses of the model were interpreted in terms of the reference design subjected to a temperature of $650^{\circ} \mathrm{F}$ and a total static distributed load of 100,000 1bs, which is approximately the summation of the weights of the fuel assemblies, control rods, control rod shrouds, and shroud support. This analysis assumes that the reactor will be loaded without water in the core, and therefore, the maximum load the support structure may have is under this condition.

The coolant water flows upward through the core. During normal operation, buoyancy effects, drag along the fuel assemblies, and pressure differentials across the support structure will substantially reduce this maximum load.

In view of the experimental results obtained from the tests performed with the model, the present or the modified design of the core support structure is considered sound and capable of carrying the mechanical load.

The small-deflection theory developed by E. Reissner, which takes into account transverse shear and normal stress deformation and considers the facing plates and core-layer to be isotropic, may be employed to determine the deflection of this type of sandwich structure. . Although the method of analysis presented in this report is partly empirical, since it is based upon data obtained from tests of beam specimens, it does provide a possible and simple means of predicting the deflections which have been found to be in satisfactory agreement with test results. 


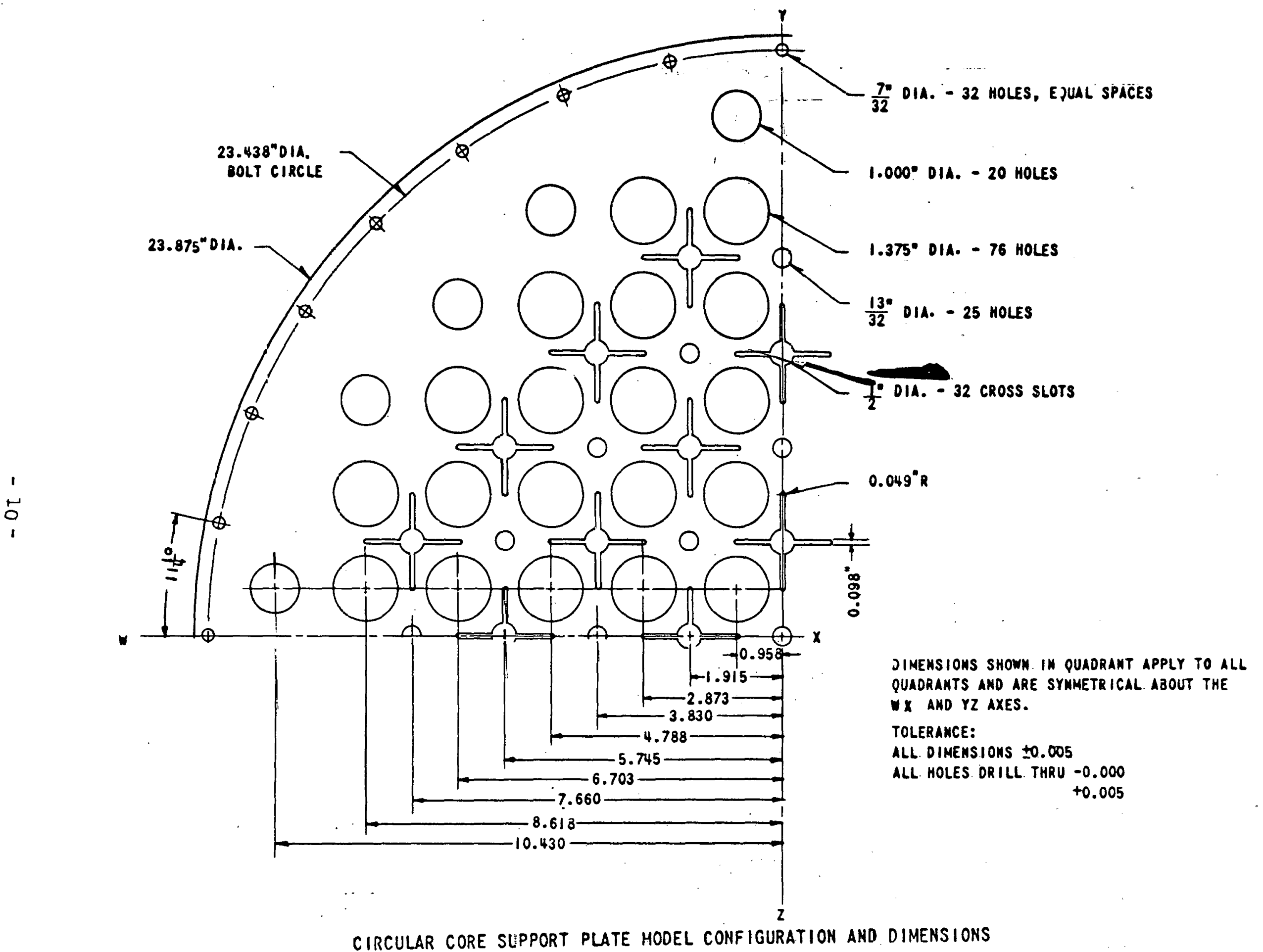

$\stackrel{1}{0}$

CIRCULAR CORE SLPPPORT PLATE MODEL CONFIGURATION AND DIMENSIONS

Figure 1 


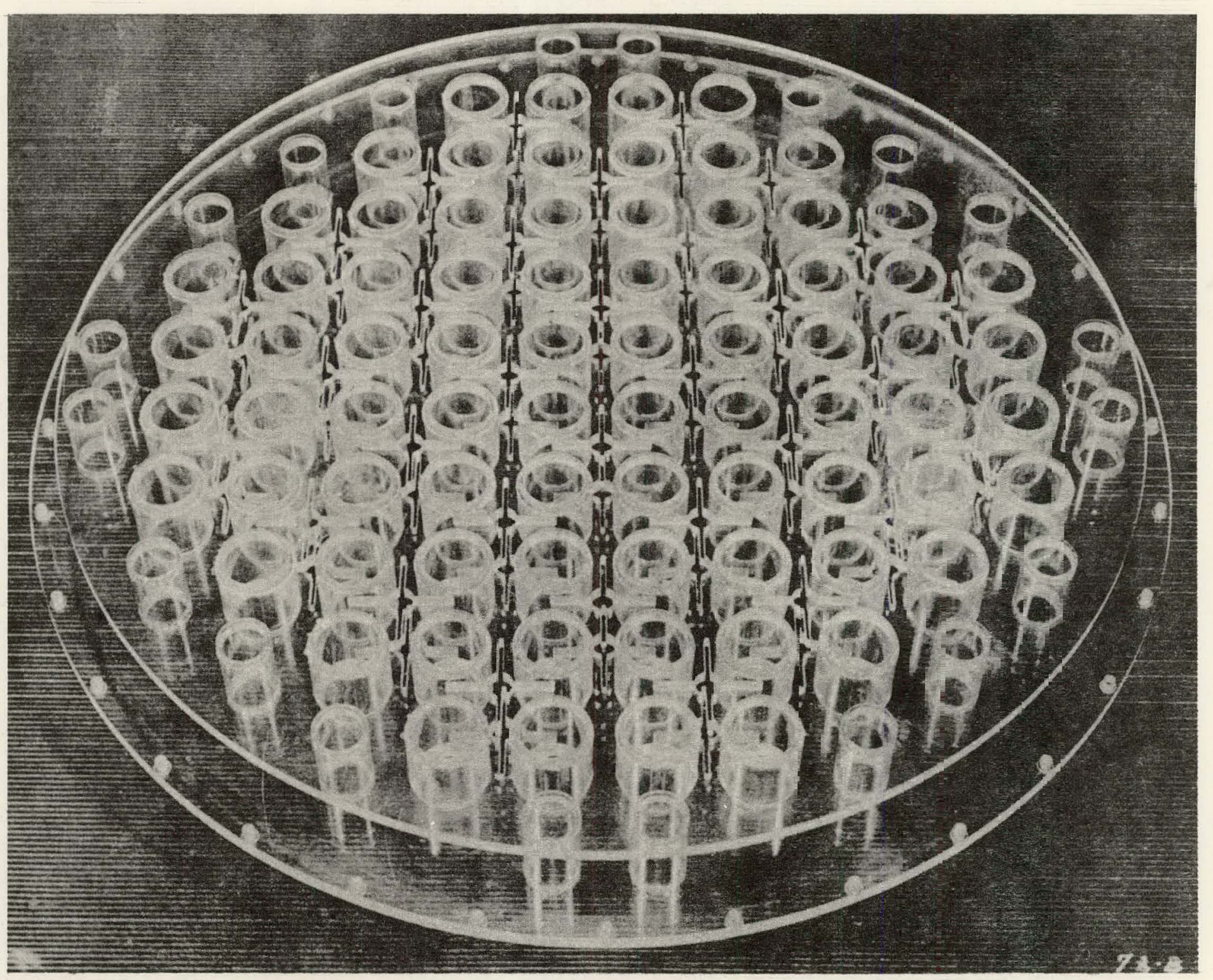

Figure 2 - Oblique View of Yankee Core Support Structure Model (No Reinforcing Rib and Water Holes) 


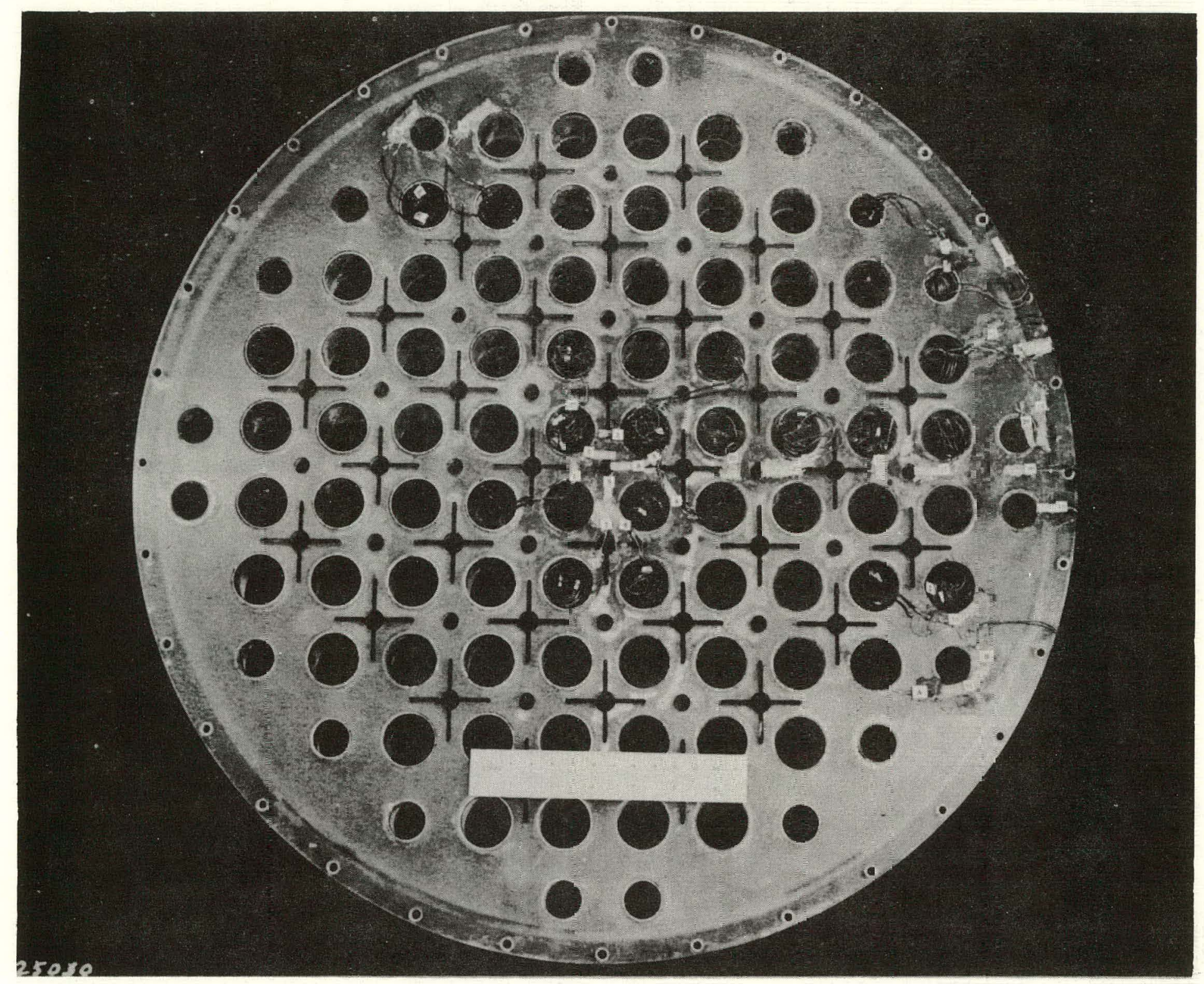

Figure 3 - Yankee Core Support Structure Model - Eottom View and Lccation cf Strain Gages 
IV. NOMENCLATURE

a

$\mathrm{b}$

C

$\mathrm{D}$

$\mathrm{D}_{\mathbf{x}}$

$\mathrm{D}_{\mathrm{qx}}$

E

G

h

I $=$ Span length of beam specimen, inches

n

n

$\mathrm{n}_{\mathbf{s}}$

$\mathbf{P}$

q

$r$

$r_{0}$

$S$

t $=$ Plate thickness, inches

$\mathrm{v} \quad=$ Poisson's ratio

y - Deflection, inches

$y^{\prime} \quad=$ Slope, Inch per inch

\section{SU BSCRIPTS}

1,2 = Top, bottom facing plate

c.

$\mathbf{f}$

$=$ Width of beam specimen, inches.

- Young.'s Modulus, psi

- Scale factor, $a_{m} / a_{p}$

- Deflection efficiency.

= Ligament efficiency.

- Total load, lbs.

= Normal load intensity, psi

- General plate radius, inches

= Radius of concentric loading, inches

- Normal bending stress, psi
- Radius of circular plate, support circular radius, inches

= Core-layer thickness, spacer height, inches

- Flexural rigidity of sandwich structure, lbs-in

- Flexural rigidity of perforated sandwich structure, lbs-in

= Shear rigidity of perforated sandwich structure, lbs-in 
V. THEORETICAI APPROACHES TO CORE SUPPORT STRUCTURE ANALYSIS

The core support structure, as previously described, is a c1rcular sandwich type structure perforated with circular holes and cruciform openings arranged according to a square array. A brief survey of the theoretical developments of the problems associated with the design of the core support structure is as follows:

\section{A. Perforated Plate}

The problem of loading a flat plate uniformly perforated with holes has been theoretically and experimentally investigated by many authors. In 1948, Gardnerl,2 proposed a plate-on-elastic foundation analysis for the perforated plate, or, in particular, a heat exchanger tube-sheet. He accounted for the weakening cffect of the holes in the plate by introducting the terms called deflection and ligament efficiencies. Miller ${ }^{3}$ in 1952, approached the problem in a similar manner with a different expression for estimating these efficiencies. In each case the plate was assumed to behave isotropically and the efficiency factors were suggested in an empirical and semi-theoretical manner. Aithough these methods are used in the empirical code rules for design, Duncan 4 has demonstrated the lack of agreement with actual experiments and has proved these methods to be inadequate.

Malkin 5 and Horvay6,7,8 in 1952 derived, independently and simultaneously, equations for determination of the elastic behavior of a triangular pitch perforated plate. According to their methods, a plate perforated uniformly by circular holes may be treated as a solid plate replacing Young's Modulus E, and Poisson's Ratio v, with fictitious values of $\mathrm{E}_{1}$ and $v_{1}$, respectively. Results of their analysis differed in the expressions of $E_{1}$ and $\nabla_{1}$ but both indicate that a plate perforated in an equilateral triangular lattice does behave isotropically. However, according to their analyses, a square pitch perforated plate would have an anisotropic behavior. Duncanl experimentally investigated the perforated plates on a triangular pitch and concluded that the test results confirmed with fair accuracy the equivalent plate constant theory proposed by Horvay. A further rational analysis of the perforated plate with edge boundary conditions, neither clamped nor simply supported was considered by Yu9. To the author's knowledge, no work has yet been done on plates perforated with cruciform openings.

B. Sandwich Type Structure

The elastic behavior of a sandwich-type structure has been extensively investigated by numerous authors in many countries. In the United States, many researches have been carried out by the Forest Products Laboratory and by the National Advisory Committee for Aeronautics. It is not feasible in this report to present a complete survey or to summarize even adequately a small portion of technical literature in 
the field of the elastic behavior of sandwich construction. Although a well compiled bibliography is listed in a special technical publication No. 118, ASTMIO, several of the more pertinent references are cited.

In 1948, Reissner11, 12, 13 derived the differential equation for the elastic behavior of a flat plate and sandwich plate taking into account the effect of transverse shear deformation. Libove and Batdorfll presented a small. deflection theory for orthotropic sandwich plates. Hoff and Mautner ${ }^{15}$ developed a theory of bending and buckling of sandwich beams subjected to transverse and axial loads by means of the principle of virtual displacement. March16, presented an approximate strain-energy solution for a flat rectangular sandwich panel, and derived an equation for orthotropic beams 18 . In 1950, Stein \& Mayers 19 proposed.a small-deflection theory for orthotropic curved sandwich plates. In the technical literature, there has been no analytical or experimental approach to the problem of sandwich type structures perforated with circular holes and cross shaped slots.

C. Rational Methods of Theoretical Analysis of the Problem

The conventional or classical plate theories in general neglect deformations due to transverse shear, an effect which has proved to be of great importance in sandwich-type construction. A literature search revealed several methods of analysis of the problem, but most methods are not likely to be of immediate practical use to the designer and engineer. However, Reissner 13, in taking into account the effect of transverse shear and normal stress deformations, derived the following simple differential equation for the elastic behavior of a circular isotropic sandwich plate:

$$
D \nabla^{2} \nabla^{2} y=q+\frac{1}{2} \frac{1}{r} \frac{d r m_{r}}{d r}-\frac{\nabla^{2} q}{\left(c+\frac{t I+t 2}{2}\right) G_{c}}
$$

$$
\text { where } \quad \nabla^{2}=\frac{I}{r} \frac{d}{d r}\left[\begin{array}{ll}
r & \frac{d}{d r}
\end{array}\right]
$$

The last term on the right of the differential equation represents the effect of transverse shear deformation. It is noted that Reissner's analysis has been restricted to the following two principal assumptions: first, the facing plates are thin and may be treated as membranes, $(t / c<<l)$, and secondly, the flexural rigidity of the core layer may be neglected, $\left(t E_{f} / C E_{c} \gg I\right)$, where $t$ is the facing thickness, $C$ is the core-layer thickness, $E_{f}$ is the elastic modulus of the isotropic facing materia], and $E_{c}$ is the elastic modulus of the core-layer material. 
For the case of a circular sandwich plate with a built-in edge, $\mathrm{m}_{\mathrm{r}}=0$, and under a uniformly distributed load, the central deflection of the problem is given by Reissner as: $13 \mathrm{Eq}$. 116

$$
y_{\max }=y_{0}\left[1+\frac{16 D}{a^{2}\left(c+\frac{t_{l}+t_{2}}{2}\right) a_{c}}\right]
$$

The above formula is modified to account for the unequal thicknesses of the two facing plates. The term $y_{0}$, is the central deflection without correction for the effect of shear deformation and is computed by the usual formulas readily obtained in standard texts. In this case

$$
\mathrm{y}_{0}=\frac{\mathrm{Pa}^{2}}{64 \pi \mathrm{D}}
$$

If the circular sandwich plate is carrying a uniformly distributed load over a concentric area of radius $r_{0}$, the solution for the central transverse deflection can be derived conventiently in a manner introduced by Reissner and is

$$
y_{\max }=y_{0}\left[1+\frac{4\left(1+2 \ln \frac{a}{r_{0}}\right) d}{r_{0}^{2}\left(\frac{a^{2}}{r_{0}^{2}}-\ln \frac{a}{r_{0}}-\frac{3}{4}\right)\left(c+\frac{t_{1}+t_{2}}{2}\right) G_{c}}\right]
$$

where

$$
y_{0}=\frac{P r_{0}^{2}}{16 \pi D}\left[\frac{a^{2}}{r_{0}^{2}}-\ln \frac{a}{r_{0}}-\frac{3}{4}\right]
$$

The above method of analysis on a circular sandwich structure is possible provided that two physical constants, the flexural rigidity and shear modulus of rigidity, are known. Considering the facing plates and the core-layer of the sandwich structure to be isotropic, the approximate expression for the flexural rigidity as given by Marchl0 is

$$
D=\frac{E_{f} t_{1} t_{2}\left(c+\frac{t_{1}+t_{2}}{2}\right)^{2}}{\left(1-v^{2}\right)\left(t_{1}+t_{2}\right)}
$$

A sandwich structure perforated with holes and cruciform openings leads to a much more complicated problem. No particular method of analysis at present is readily available. Since the facing plates of the sandwich structure are assumed to take all the direct bending stress, it can be extended immediately to the problem of the single uniformly perforated. thin plate. Similarly, a perforated sandwich structure may be considered as a modified homogeneous sandwich structure. The flexural rigidity $D$, of the homogeneous sandwich structure is replaced by $D_{x}$, such that $D_{x}=n_{w} D$, where $n_{w}$ is the deflection efficiency determined from experiment. 
The shear modulus of rigidity $G_{c}$, of the core-layer, can be evaluated by means of tests conducted on sandwich beam specimens whose geometrical configuration is similar to an element of the core support structure, and computed by the following formula as given in the Military Standard, MII-STD-401 A25:

$$
G_{c}=\frac{P L C\left[\left(\frac{L}{L_{g}}\right)^{2}-1\right]}{2 y(h+c)^{2} b\left[\frac{P y_{3}}{P_{g} y}\left(\frac{L}{L_{g}}\right)^{3}-1\right]}
$$

where $P$ is the total load applied to the simply supported specimen at two quarter-span points, $y$ is the mid-span deflection, $L$ is the long span length, and subscript $\mathbf{s}$ is denoting a short span length. The specimens are first tested over a long span and then cut into shorter lengths and tested in the same manner to eliminate the effect of shear deformation in the core material.

For the conceptual design of the Yankee core support structure model, the calculated value of the flexural rigidity $D$, by equation (6), is $24.2 \times 104$ lbs-in. Using the deflection efficiency $n_{W}=0.306$, as obtained experimentally later in this report, the flexural rigidity of the perforated sandwich structure model $D_{x}$, is $7.42 \times 104$ Ibs-in. From the load deflection curve data collected from the beam specimen tests, $\mathrm{G}_{\mathrm{c}}$ was computed by equation (7) to be $1290 \mathrm{psi}$. The central deflection $y_{0}$, for a total uniformly concentric load of 136.9 lbs., was calculated by equation (5) to be $1.887 \times 10^{-3}$ inch.

Substituting the numerical values of $\mathrm{y}_{0}, G_{c}$ and $D_{x}$, respectively into equation (4), the central deflection of the circular sandwich structure model is found to be 0.00921 inch. The measured central deflection on the model was 0.0096 inch as shown in Figure 21. Hence, the analytical method suggested for analyzing this type circular sandwich structure gave a central deflection 4.4 per cent smaller than the observed value.

\section{EXPERIMENTS ON MODELS}

\section{A. Similarity of Model and Reference Design}

The reduced-scale models as designed for this experiment are geometrically similar to the reference design. In order to evaluate the full scale characteristics of the reference design accurately from the behavior of the model, it is necessary that the properties of model material be subject to the following conditions for perfect similarity:

1. Model material must deflect in a linear, elastic manner, that is, must follow Hooke's Law.

2. Relative unit strains must be the same if the stress at a point in the structure is not linear with load.

3. Poisson's ratio should be the same as that of the reference design material. 
Plexiglas II UVA was selected as the model material in this study. It is a cast thermo-plastic acrylic resin sheet manufactured by the Rohm and Haas Company. It has the very desirable properties of low modulus of elasticity, is readily mabhined, and essentially fulfills the first two aforesaid conditions. In addition, its elastic properties vary with temperature and humidity. It creeps under a constant load and Poisson's ratio for it is larger than that for stainless steel. However, the effect of temperature variation on Young's Modulus can be corrected with the experimental data from the manufacturer. Static tension creep tests on Plexiglas strip specimens were conducted and results indicated that the deflection was approximately constant when the load was applied for at least three minutes. The effect of a difference in

Poisson's ratio usually produces larger deformation and stress in the structure made from the material with the larger Poisson's ratio. Thus, the effect tends to give model test results that are conservative.

Table 1 lists some of the properties of the materials and parameters for the model and reference design:

Table 1

Comparis on of Parameters and Properties of Model and Reference Design

\begin{tabular}{|c|c|c|}
\hline Properties and Parameters & $\begin{array}{l}\text { Reference } \\
\therefore \text { Design. }\end{array}$ & Model \\
\hline a. Material & AISI 304 ss & $\begin{array}{l}\text { Plexiglas II } \\
\text { UVA }\end{array}$ \\
\hline b. Operating temperature, $9 \mathrm{~F}$ & 650 & 75 \\
\hline $\begin{array}{l}\text { c. Relative linear dimensions, } \\
\text { a, inches }\end{array}$ & 1 & 0.250 \\
\hline d. Total load, P, Ibs. & 1000 & 1 \\
\hline e. Young's Modulus, E, psi & $25 \times 106$ & $0.455 \times 10^{6}$ \\
\hline f. Relative strain, $\left(\frac{P}{a^{2} E}\right)$, in/in & $4 \times 10^{-5}$ & $3.52 \times 10^{-5}$ \\
\hline g. Poisson's Ratio, v & 0.317 & 0.35 \\
\hline
\end{tabular}


By the method of dimensional analysis, the model test results may be interpreted in terms of the reference design as follows:26, 27,28

1. The reference design elastic deformation is determined from the model tests by the equation:

$$
\begin{aligned}
y_{p} & =n \frac{P_{p}}{P_{m}} \frac{E_{m}}{E_{p}} f\left(v_{m}, v_{p}\right) \\
& =\frac{1}{4} \times \frac{1000}{1} \times \frac{0.455 \times 106}{25 \times 106} f\left(v_{m}, v_{p}\right) y m \\
& =4.5 f\left(v_{m}, v_{p}\right) y_{m}
\end{aligned}
$$

2. The elastic change in slope of the reference design surface is given by:

$$
\begin{aligned}
y_{p}^{\prime} & =n^{2} \frac{P_{p}}{P_{m}} \frac{E_{m}}{E_{p}} f\left(v_{m}, v_{p}\right) y_{m}^{\prime} \\
& =\frac{1}{16} \times \frac{1000}{1} \times \frac{0.455 \times 10}{25 \times 106} f\left(v_{m} ; v_{p}\right) y_{m}^{\prime} \\
& =1.125 f\left(v_{m}, v_{p}\right) y_{m}^{\prime}
\end{aligned}
$$

3. The reference design stress is related to the model stress by the equation:

$$
\begin{aligned}
s_{p} & =n^{2} \frac{P_{p}}{P_{m}} f_{1} \quad\left(v_{m}, v_{p}\right) s_{m} \\
& =\frac{1}{16} \times \frac{1000}{1} f_{1}\left(v_{m}, v_{p}\right) \cdot s_{m} \\
& =62.5 f_{1}\left(v_{m} ; v_{p}\right) s_{m}
\end{aligned}
$$


The function $f\left(v_{m}, v_{p}\right)$ represents the effect of Poisson's ratio difference between the model and reference design materials, and is indeterminate. However, it has been estimated from the proposal. of Leven 29 , that this unknown function would have the following values:

$$
\begin{aligned}
& \text { Plate bending only: } f\left(v_{m}, v_{p}\right)=\frac{1-v_{m}^{2}}{1-v_{p}^{2}}=0.9754 \\
& \text { Shear stress only: } f\left(v_{m}, v_{p}\right)=\frac{1+v_{p}}{1+v_{m}}=0.9756
\end{aligned}
$$

The effect of Poisson's ratio difference in this case is indicated to be small. For simplicity and conservatism, the functions $f\left(v_{m}, v_{p}\right)$ may be assumed to be equal to unity.

B. Test Specimens

Five types of circular plate specimens of plastic material designated Plexiglas II UVA were tested. The 0.D. of all the circular plates is $23.875^{\prime \prime}$, and the bolt circle is $23.438^{\prime \prime}$ in diameter for the 32-7/32" diameter bolt holes. Each tested specimen was carefully machined to close tolerance and geometrically similar to the reference design in one-quarter scale. Description of each type of plate specimens is: tabulated in Table 2.

Young's Modulus of Elasticity of the Plexiglas was determined experimentally. Two types of strip specimens, $0.500^{\prime \prime} \mathrm{x} 10^{\prime \prime}$ and $1.00 " \mathrm{\prime} \times 10^{\prime \prime}$ cut from stock sheets used in fabricating the model specimens, were tested under a series of loads applied at two-quarter-span points with simple end supports. Fourteen test specimens of various thicknesses were tested. From their experimental data, the Modulus of Elasticity was calculated by the simple beam equation. The average value of Young's Modulus of the Plexiglas II UVA is found to be 455,000 psi at $75^{\circ} \mathrm{F}$.

Typical sandwlch beam specimens are shown in Figure 7. The dimensions of beams are 23.438" in span length by $1.915^{\prime \prime}$ in width, and the geometry is similar to an element of the core support structure. The variable parameters are: the thickness of the bottom beam, and the height and wall thickness of the inserted cylindrical spacers. Descriptions of the sandwich beam specimens are summarized in Table 3: 


\section{TABLE 2 - DESCRIPTION OF CIRCULAR PLATE SPECTMENS}

No. Type of Specimen

1

Solid Plates

Perforated Plates, Circular Holes

(Figure 4)

3 Perforated Plates, Cruciform openings (Figure 5)

4 Perforated Plates, Circular holes and Cruciform openings (Figure 6)

(a) $0.374 \pm 0.013$
(b) $0.375 \pm 0.011$
(c) $0.378 \pm 0.015$
(d) $0.382 \pm 0.016$

5 Yankee Model, double plates, (Figure 2 \& 3)

To $>$ Plate $0.315+0.007$ Bottom Plate 0.375 土 0.010
For all types of specimens:

O.D. $=23,875^{\prime \prime}$ and

B.C. $=23,483^{\prime \prime}$ for

(32) $-7 / 32$ " diameter

bolt holes.

76 - 1.375" dia. and $20-1.000^{\prime \prime}$ dia. holes at 1.915" pitch of sq. pattern

$32-0.098^{\prime \prime} \times 2.013^{\prime \prime}$ cross slots, $1 / 2 " d i a$. hole at center.

Pitch $=1.015^{\prime \prime}$

Combination of types 2 and 3

Overall height $2^{\prime \prime}$. 1/4 "reinforced circular rib. Top plate $0 . D_{0}=22.250^{\prime \prime}$. Cylindrical spacer $1-1 / 2^{\prime \prime}$ O.D. $\times 1-1 / 4^{\prime \prime}$ I.D.

\section{Purpose of Test}

To confirm theoretical formulae for stress and deflection and to verify the experimental method.

To obtain deflection and strains, and calculated deflection and ligament efficiencies.

To obtain deflection and strain, and calculate deflection and ligament efficiencies.

To obtain deflection and strain, and calculate deflection and ligament efficiencies.

To obtain deflection and stress.

* For detail dimensions, See Figure 1. 


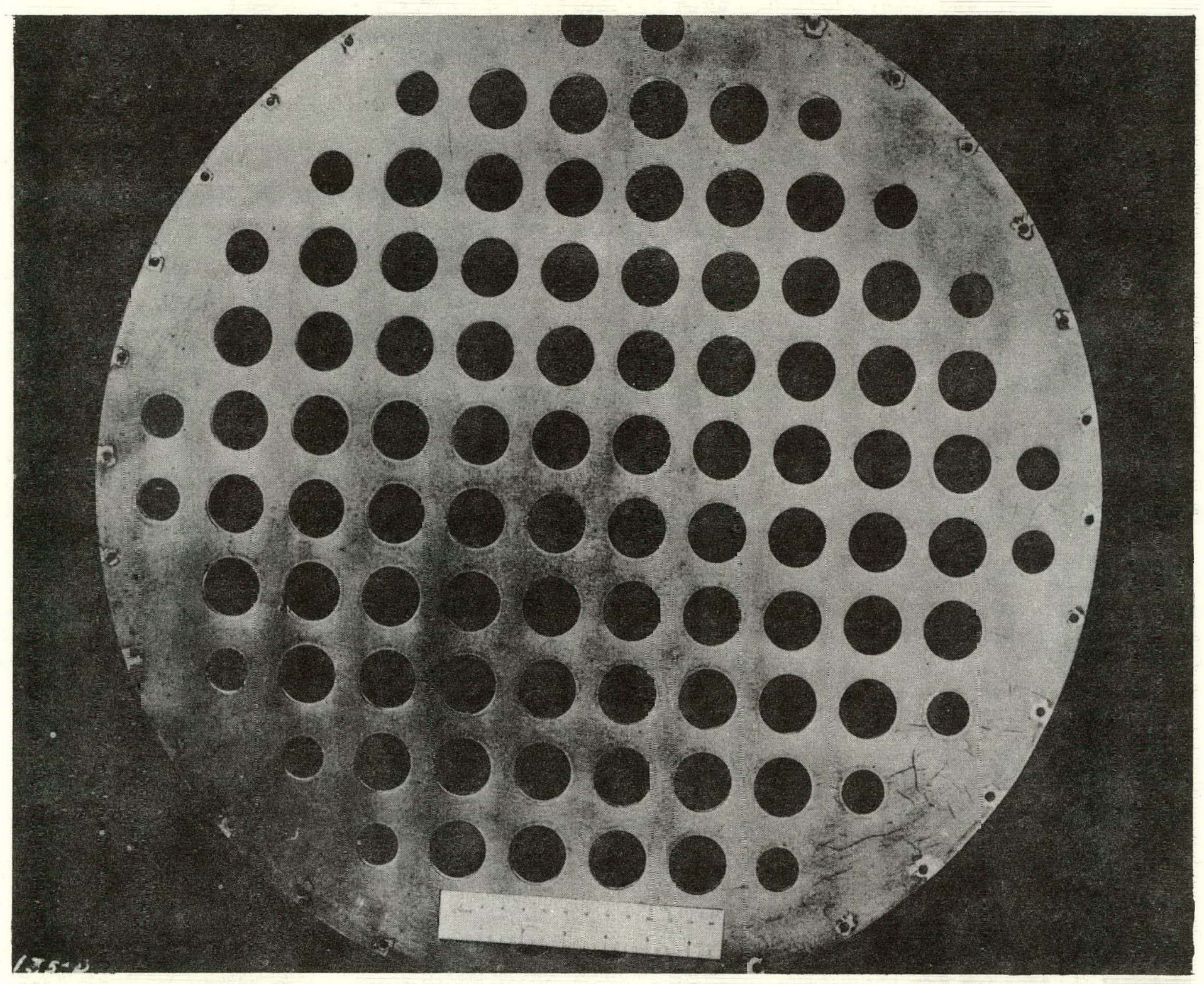

Figure 4 - Plate Model Perforated with Circular Holes 


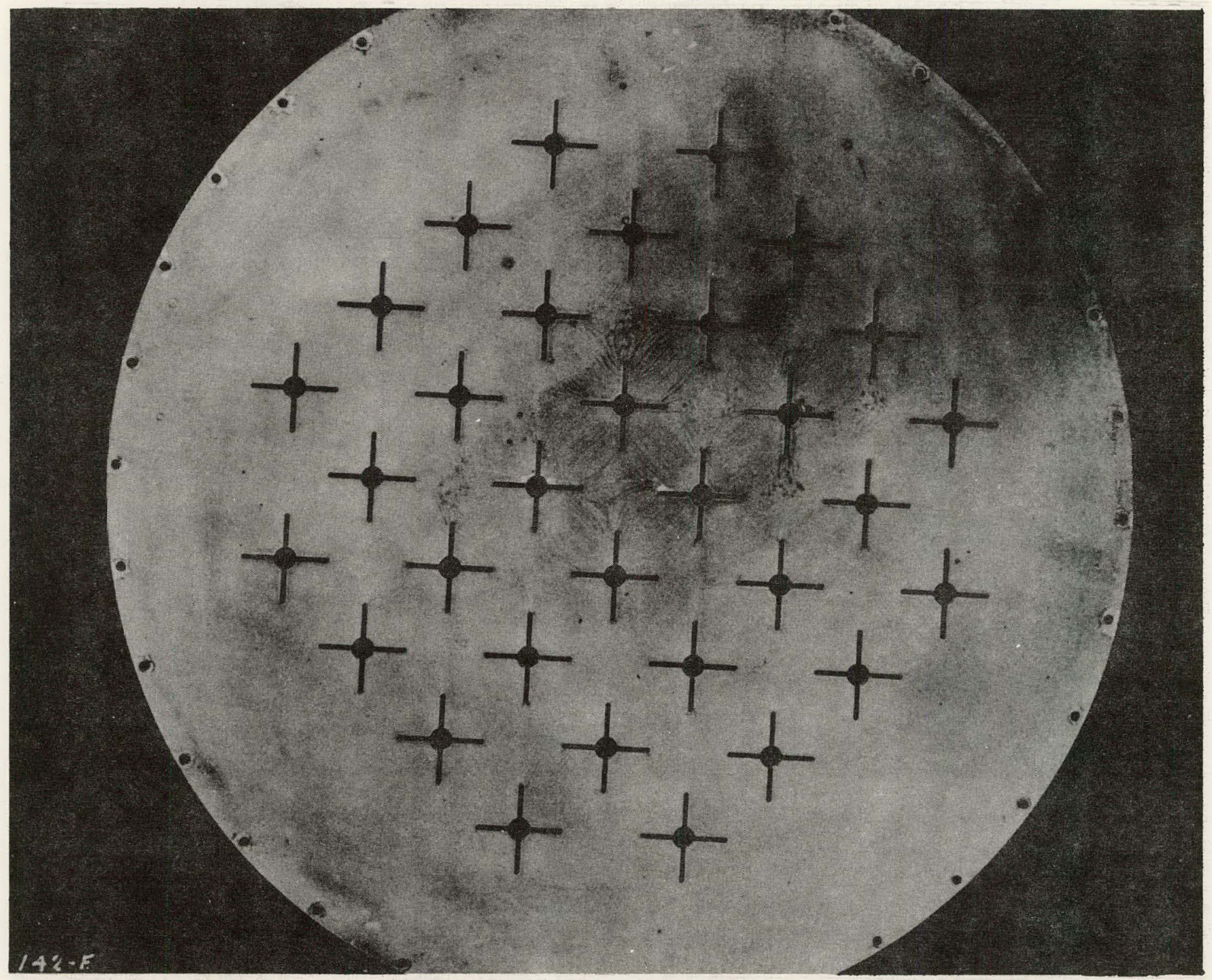

Figure 5 - Plate Model Perforated with Cruciform Openings 


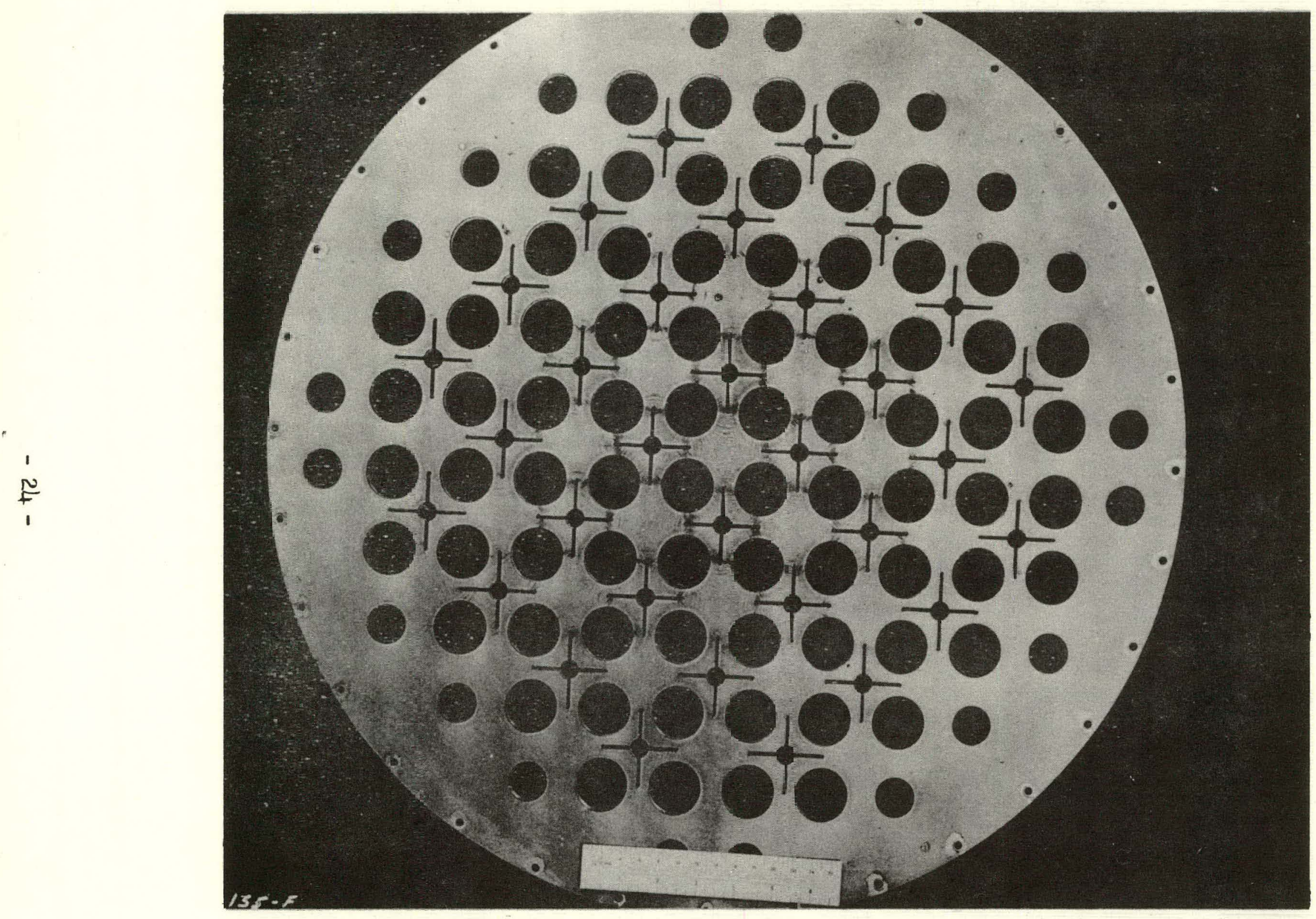

Figure 6 - Plate Model Perforated with Holes and Cruciform Openings 
Table 3

Description of Sandwich Beam Specimens

\begin{tabular}{|c|c|c|c|}
\hline No. & $\begin{array}{l}\text { Beams, Thickness } \\
\text { inch }\end{array}$ & $\begin{array}{c}\text { Inserted Cylindrical } \\
\text { Wall Thickness, } \\
\text { inch }\end{array}$ & $\begin{array}{l}\text { Overal1 } \\
\text { Height, } \\
\text { inches }\end{array}$ \\
\hline 1 & $\begin{array}{l}\text { Top: } 0.312 \pm .007 \\
\text { Bottom: } 0.375 \pm: 008\end{array}$ & 0.125 & 0.690 \\
\hline 2 & $"$ & $"$ & 1.000 \\
\hline 3 & $"$ & $"$ & 2.000 \\
\hline 4 & $"$ & $"$ & 3.000 \\
\hline 5 & $"$ & 0.250 & 2.000 \\
\hline 6 & $"$ & 0.063 & 2.000 \\
\hline 7 & $\begin{array}{l}\text { Top: } 0.312 \pm .007 \\
\text { Bottom: } 0.417 \pm .010\end{array}$ & 0.125 & 2.000 \\
\hline
\end{tabular}

The Yankee core support structure model is shown in the bottom and oblique views in Figure 2 and Figure 3, respectively. The model is in one-quarter scale and is geometrically similar in all significant details to the reference design lower core support structure. The dimensions and configuration of the plate model are presented in Figure 1. All the cylindrical spacers and the reinforcing rib were cemented to the top and bottom plates with ethylene dichloride solution to form a rigid sandwich-type structure.

\section{Test Apparatus}

The model testing apparatus, as shown in Figures 8 and 10, consists

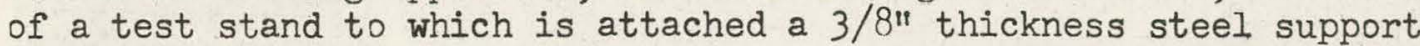
plate with a 23.000" diameter opening at the center. Each specimen model is mounted to the support plate from the bottom by $32-1 / 4$ " Allen Head bolts at a 23.438" diameter bolt circle. To insure the peripheral rigidity of the support plate, a hexagonally shaped structure made of $1-1 / 2 \times 1-1 / 2 \times 1 / 4^{\prime \prime}$ angles is welded around the opening. Another 1/4" thickness steel plate is attached underneath to the support framework by four I" diameter rods for the purpose of positioning the deflection dial indicators.

Various circular plate specimens were tested under two types of loading:

1. Uniform air pressure over a concentric area equivalent to the core average cross section area. 

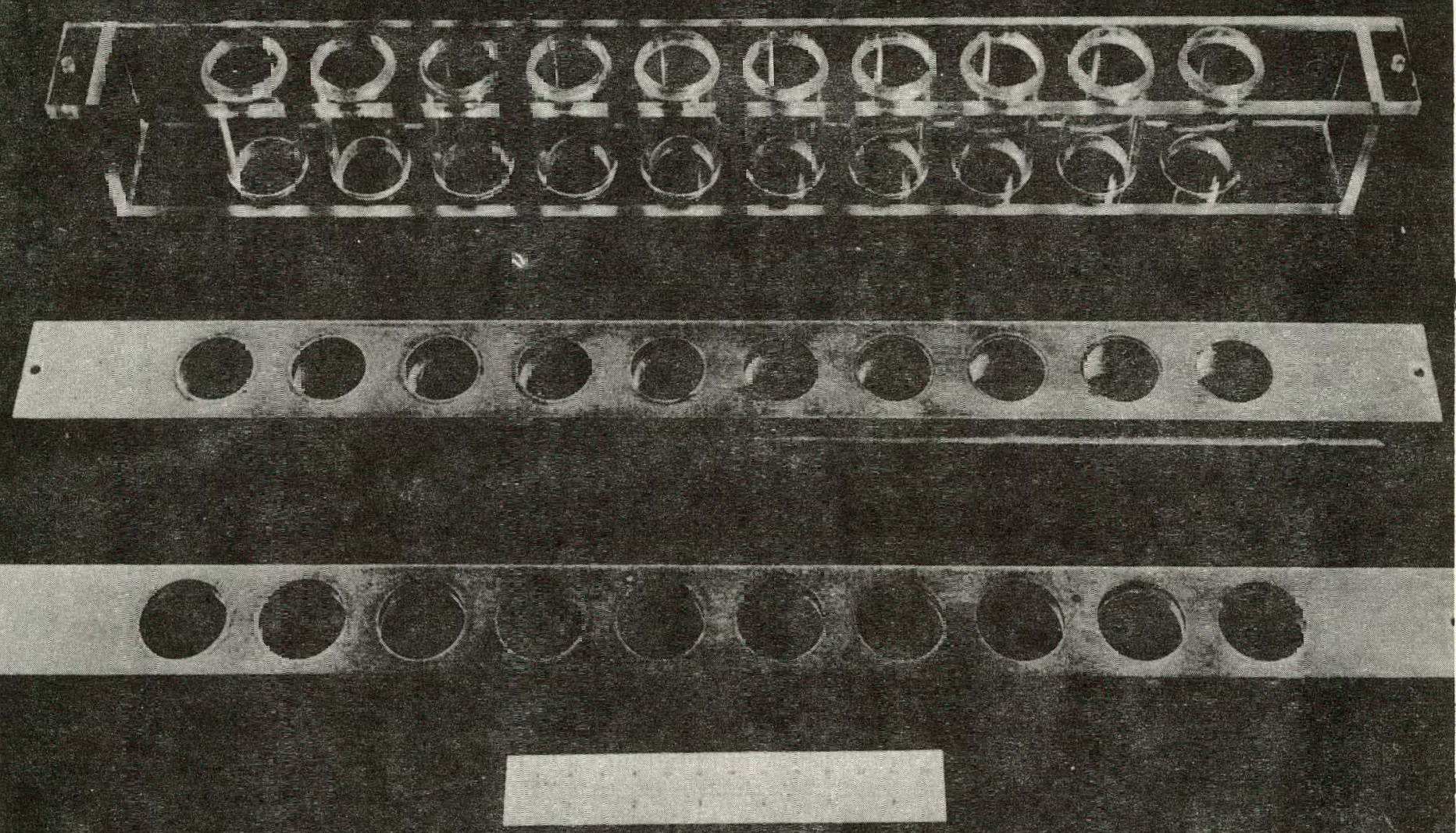

Typical Sandwich Beam Specimens

Figure ? 
2. 76 columns of steel washers simulating the weight of 76 fuel assemblies loaded on the periphery of 76 circular holes.

The apparatus, designed to apply a uniformly distributed load to the top facing of the circular plate specimens, is shown pictorially in Figure 8, and schematically in Figure 9. The apparatus consists of a 26" diameter by 1/4" thick circular steel plate, two knife edge steel rings, and a diaphragm made of $1 / 32^{\prime \prime}$ thick rubber gasket material. The thin rubber diaphragm, applied to the edge with sealing cement, is tightly fastened by means of $24-1 / 4$ " bolts between the two steel rings, which are in turn attached to the circular plate to form a circular air chamber. Uniform load over a concentric area of the plate specimen in produced within the perimeter of the 18.84" diameter knife edge of the steel ring by introducing air pressure into the chamber. The inlet air pressure is controlled by a pressure reducer and measured with a 30" Merian U Type manometer and two U.S. pressure gages of the range $\mathrm{O}-35^{\prime \prime} \mathrm{H}_{2} \mathrm{O}$ and $0-15 \#$, respectively. The circular air chamber is clamped to the support plate to prevent its being lifted under load and is adjusted into position in such a manner until it touches the top surface of the test specimens.

A non-uniformly distributed load simulating the reactor core individual fuel assemblies is applied to the plate specimen by means of 76 columns made of $1-1 / 2^{\prime \prime} \mathrm{O} . \mathrm{D}$. by $25 / 64^{\prime \prime} I . D$. by $3 / 32^{\prime \prime}$ steel washers as shown in Figure 10, Each hanging rod and a group of 5 washers are actually weighed, and their average values are used to calculate the total dead-weight load. The 76 columns of steel washers can be lifted at one time by means of a lifting support plate and can also be loaded precisely on the periphery of the fuel assembly support sleeves. This non-uniformly distributed total load is increased by adding an increment of 5 washers to each hanging rod.

Deflections of each plate specimen are measured by means of 4 Starrett jeweled bearings \#656-617, and 4 Tumico Model BC-1, 0.0001" graduation dial. indicators, all with magnetic base indicator holders, located at different radii. One Federal Testmaster, Model 2, $0.0001^{\prime \prime}$ gradua tion dial gauge is positioned at the bolted circle to check the deflection, if any, at the edge boundary.

Strains or stresses are measured by means of electrical resistance SR-4 Type A-19, strain-gages made by the Baldwin-Lima-Hamilton Corp. The flat grid, fast-drying paper strain-gage has an electrical resistance of $61 \pm 0.5 \mathrm{ohms}$, and a gage factor of $1.61 \pm 3 \%$.

The 1/8" SR-4 strain-gages are connected to a Baldwin-Lima-Hamilton 20 Channel Switching and Balancing Unit Model PSBA-20 with \#26 wire. Strains are measured by an Ellis Associates BAM-I Bridge Amplifier and Meter, or by a Baldwin Type M Portable Strain Indicator. Both the Ellis meter and the Baldwin Indicator were tried and the results obtained were in close agreement. The latter showed a longer drift period to read constant and involved the calculations of the measured 


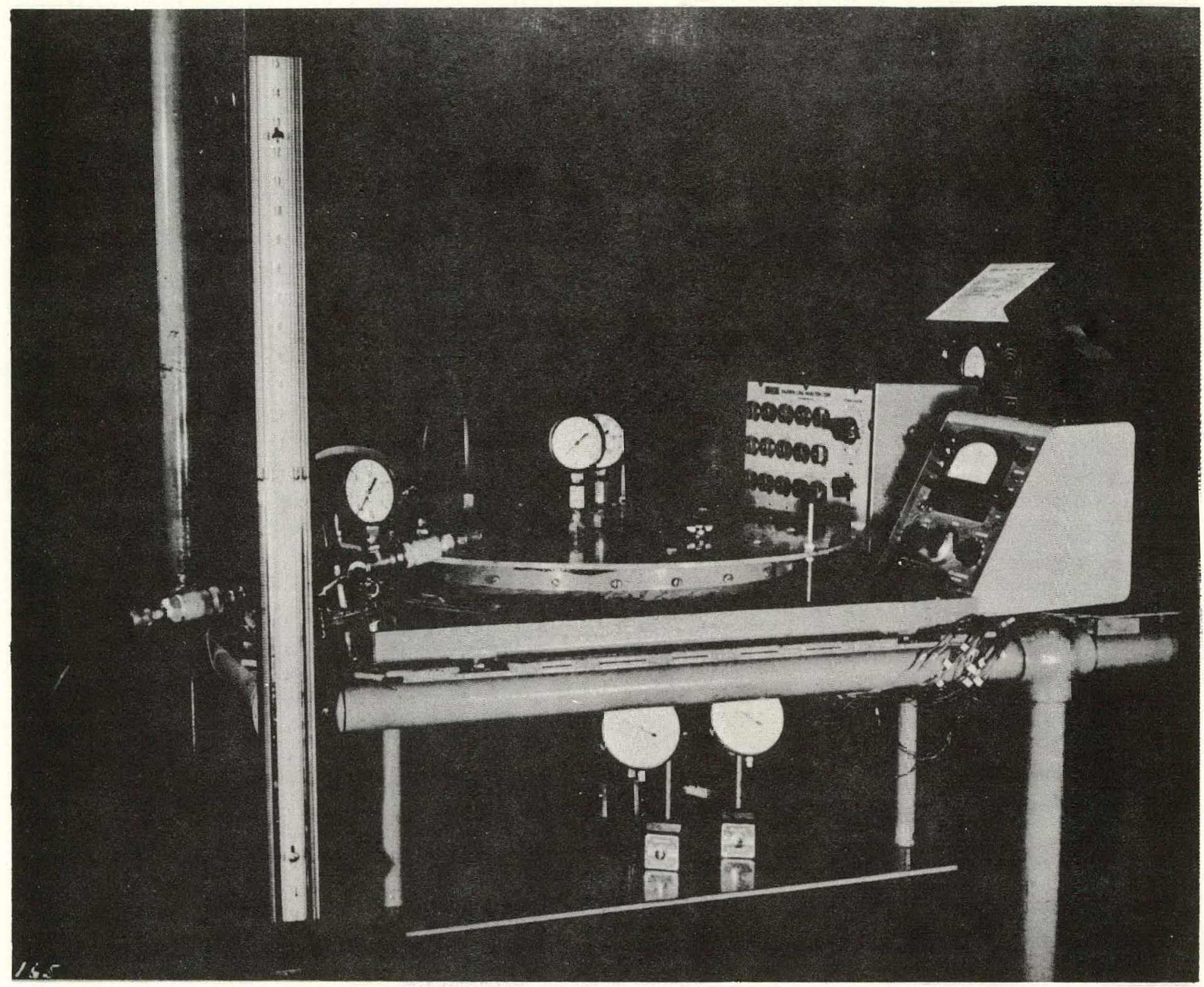

Test Apparatus for a Uniform Air Pressure Loading Cver a Corcentric Sircular Area 


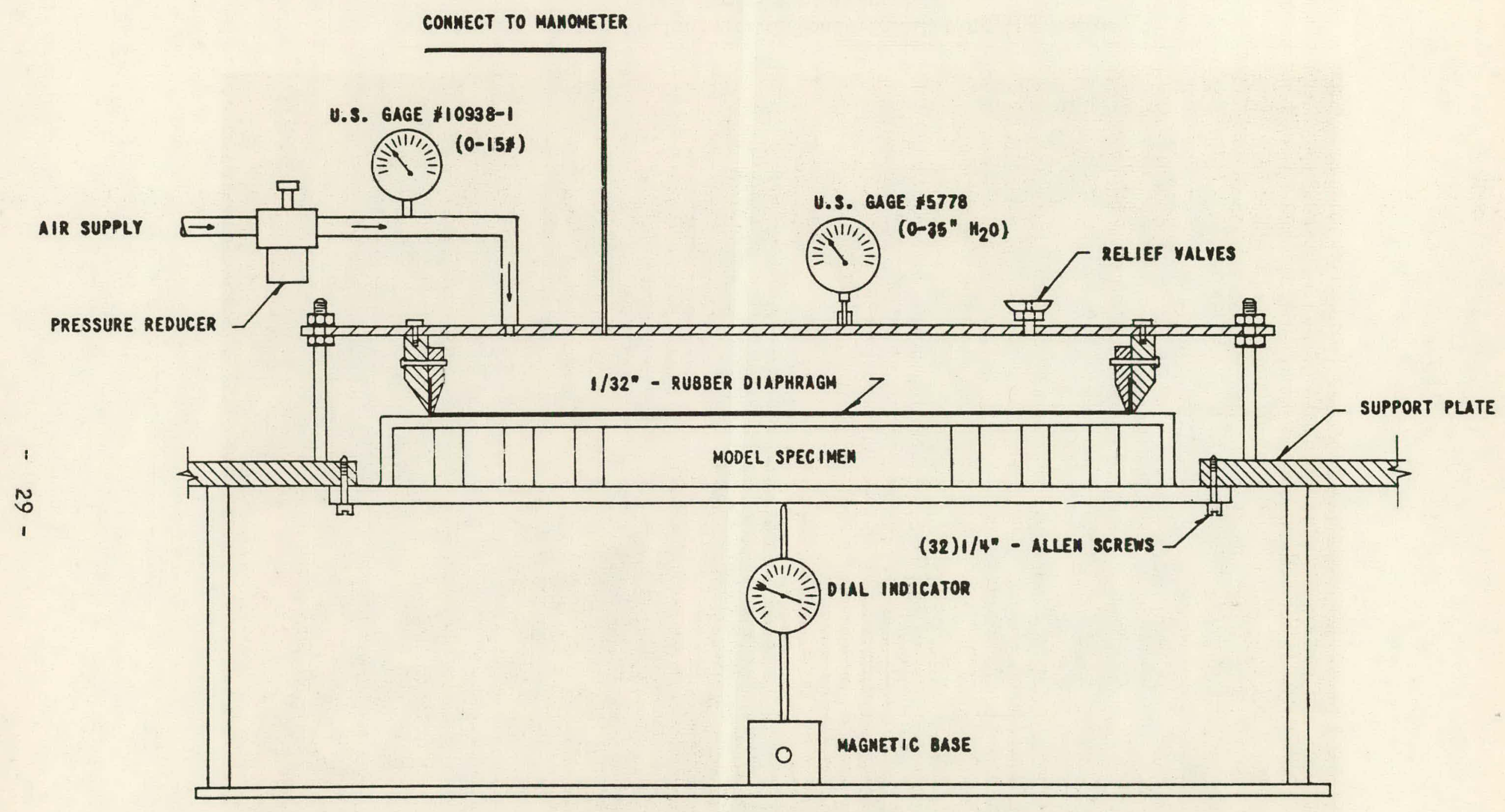

SCHEMATIC DIAGRAM OF APPARATUS FOR A UNIFORM AIR PRESSUFE LOADING OVER A CONCENTRIC AREA

Figure 9 


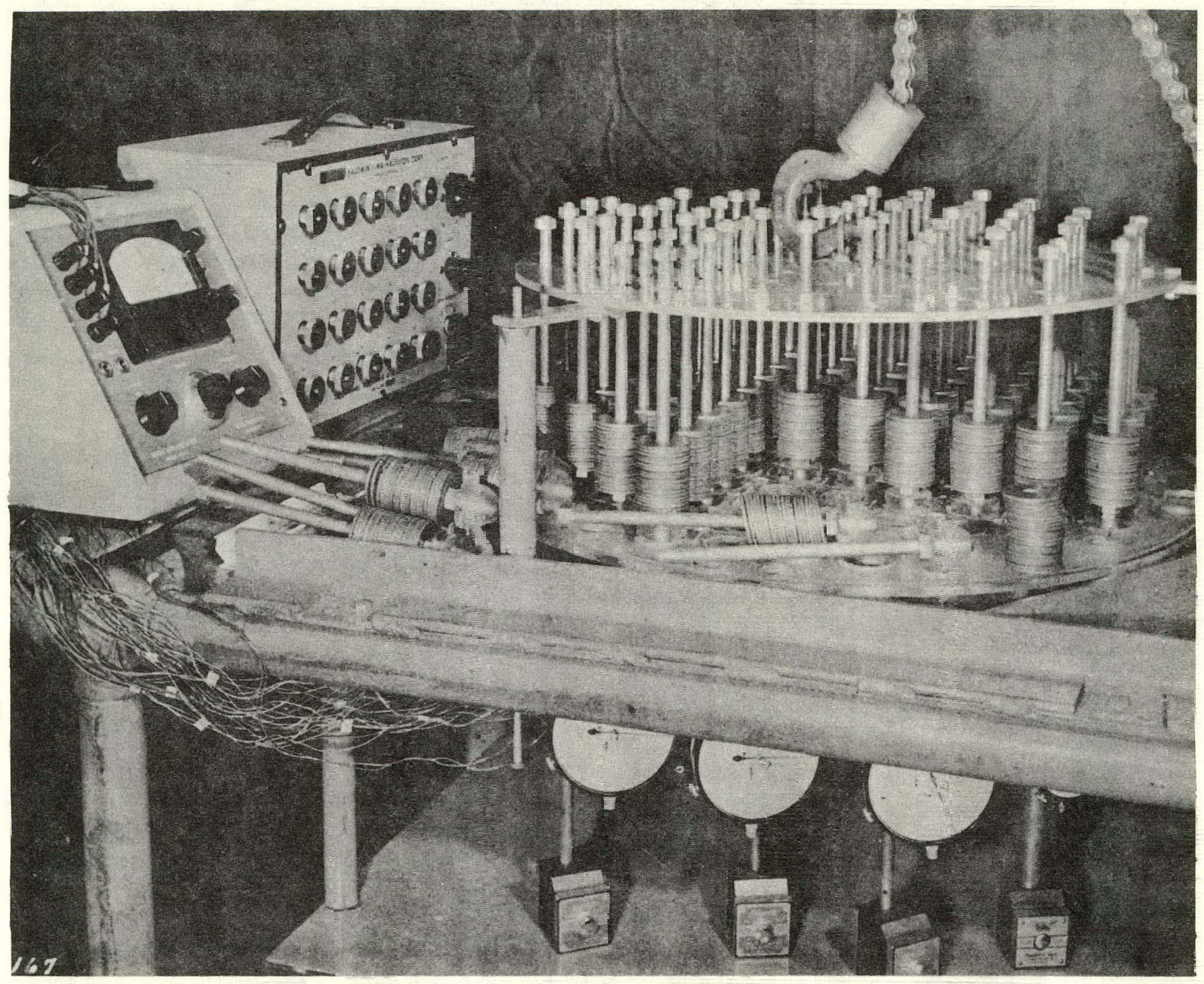

Test Apparatus for 76 Individual Loads Simulating the Weight of the Fuel Assemblies

Figure 10 


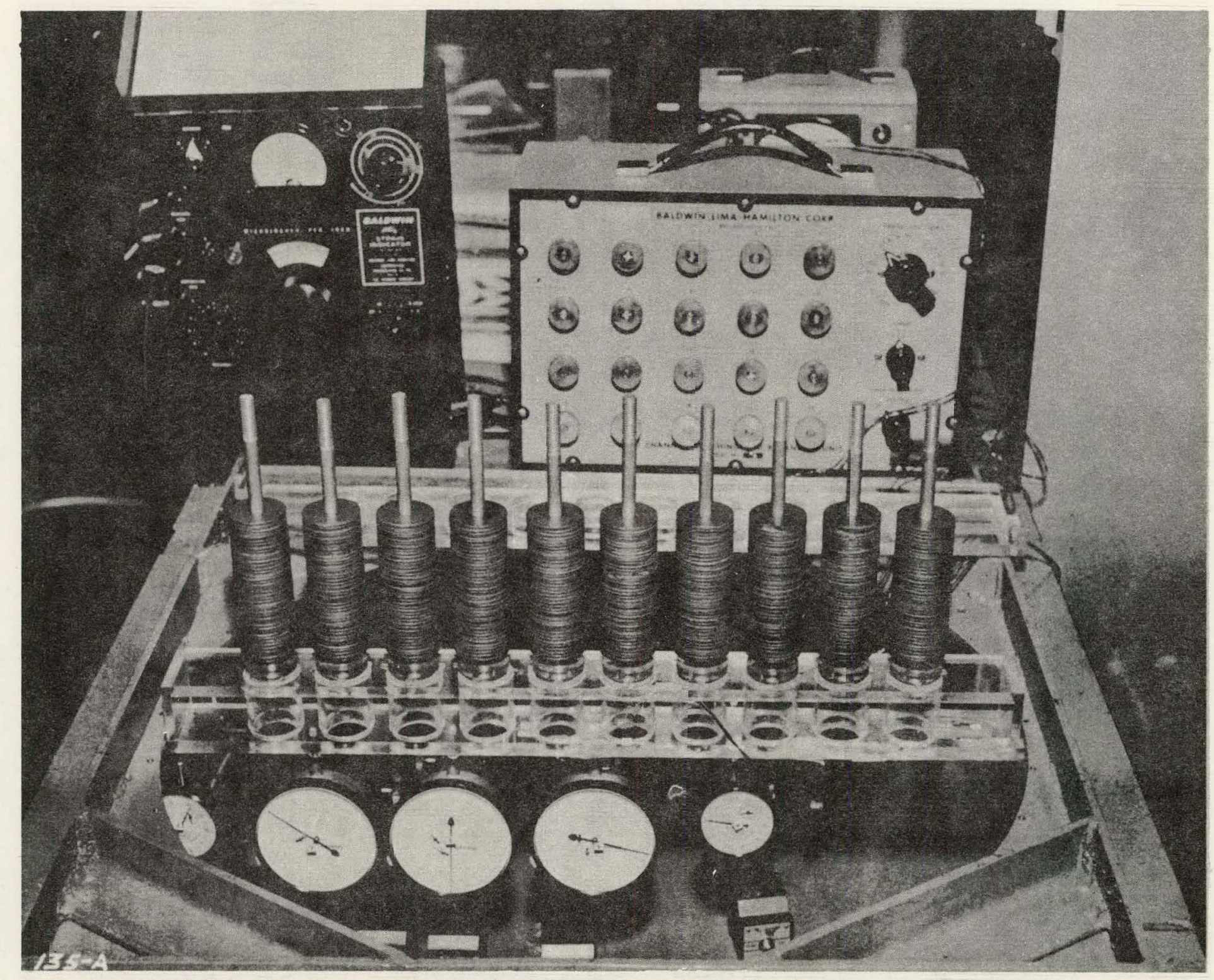

Test Apparatus for Sandwich Beam Specinens

Figure 11 
strain, the stress, and the gage factor correction, while the former measured the stresses directly by the calibration setting of the meter. Therefore, the Ellis Associates meter was used throughout all the subsequent tests.

\section{Test Procedure}

The method of carrying out the tests was essentially the same for all plate models, and any special conditions will be described later when referring to the individual experiments. The general procedure is as follows:

1. Plate models were tested for deformation under a uniformly dislributed air pressure loading and then under 76 individual deadweights as described previously. The load was applied in an increment at the rate of approximately 10 lbs. per minute.

2. Stresscoat was sprayed on various types of perforated plate models as a preliminary test to locate regions of high stress concentrations and direction of the maximum principal strains, and to observe the start and spreading of crack patterns as the loads were increased.

3. Strains were measured with electrical strain-gages on the indicated high stress region. Tests were conducted under two types of loading as in step 1 .

4. Sandwich beam specimens were tested for deformation under various loading and boundary conditions.

5. Yankee core support structure model was tested for deflections and stresses.

Relative deflection measurements were made at different radial locations with reference to a point on the bolted circle. The average of several readings at the center or at points with the same distance from the center was recorded as resulting deflection. In the case of plate perforated with a hole at the center, the maximum deflection was measured at the periphery of the hole. Complete load-deflection data were taken in each case by means of nine 0.0001" dial indicators. All the plate specimens were mounted to the steel support plate by 32-1/4" Allen Head screws with a measured torque of approximately $0.45 \mathrm{ft}-\mathrm{lbs}$. on each screw. Then zero deflection was set on the dial indicators, and a reading was taken approximately 3 minutes after the load was applied.

The core support plate models are in such complex form that it is impossible to predict where the maximum stress levels occur. In order to obtain an overall picture of the surface stresses and to locate regions of dangerous stress concentrations, Stresscoat No. ST 12045 was sprayed on the test specimens. The selection of this coating is made on the basis of the wet-and-dry bulb phychrometer readings of 
$56^{\circ} \mathrm{F}$ and $73^{\circ} \mathrm{F}$, respectively, in the test area. A concentric air pressure loading was used in this test. The load was applied in an increment of $1^{\prime \prime} \mathrm{H}_{2} \mathrm{O}$ air pressure until the first crack in the lacquer was observed. The formation. of final cracking pattern by reapplying a greater load was then photographed. To render the crack patterns in the Stresscoat. more visible and to simplify the photography, a red dye etchant (ST-1300) was applied to the coated surface.

With the information on the principal stress directions and the location of the points or regions of high strain obtained from the Stresscoat test, electrical strain-gages were placed on the plate specimens with considerable economy in time and in quantities of strain gages. This made possible a complete description of the stress field with only two strain gages: one gage was oriented in the direction perpendicular to, while another in parallel to, the stress trajectories. This procedure was applied to all the plate epecimens to measure the major and minor principal stresses. Tests were again conducted under two types of loading as in the deflection test. Stress readings were made at approximately $10 \mathrm{lb}$. increments to establish the load-strain relationships at the gage locations.

Various sandwich beam specimens were tested under the following loading and boundary lconditions:

1. Simply supported, loads applied at two quarter-span points, 2. Simply supported, loads applied at ten points.

3. Bolted, loads applied at ten points.

The setup for the bending tests is shown in Figure 11. The central deflection was measured by means of a dial gage. The purpose of . these tests is twofold. The main purpose is to obtain an optimum design of this sandwich type structure on the variable parameters as listed in Table 3. Secondly, it is to determine the flexural and shear rigidity of the structure with the aid of the theoretical deflection formulas. The Yankee core support structure model was. then designed based on the results obtained from the optimization study.

E. Test Results

1. Plate Models:

In order to verify the correlation between the theoretical and experimental method, a test of two circular solid plates of different thickness were conducted under a uniform distributed load over a concentric circular area. Both the calculated and observed deflections and stresses of the model and the prototype were compared as shown in Figures 12 and 13. Treating the actual 

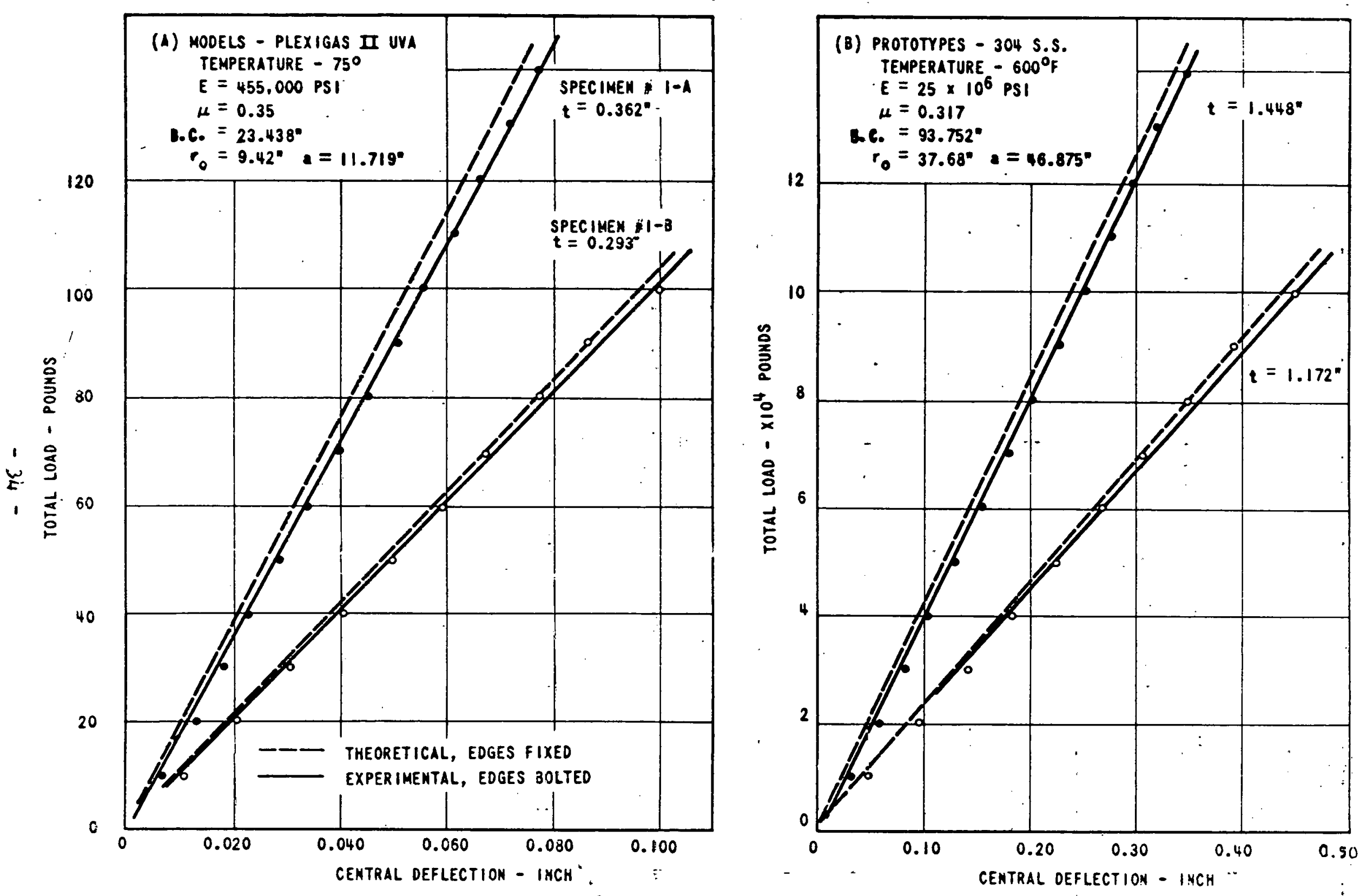

COMPARISOII OF EXPERIMENTAL AND THEORETICAL DEFLECTION OF GIRCULAR PLATES UNDER CONCENTRIC UNIFORMLY DISTRIBUTED LOAD OF RADIUS $r_{0}$ 

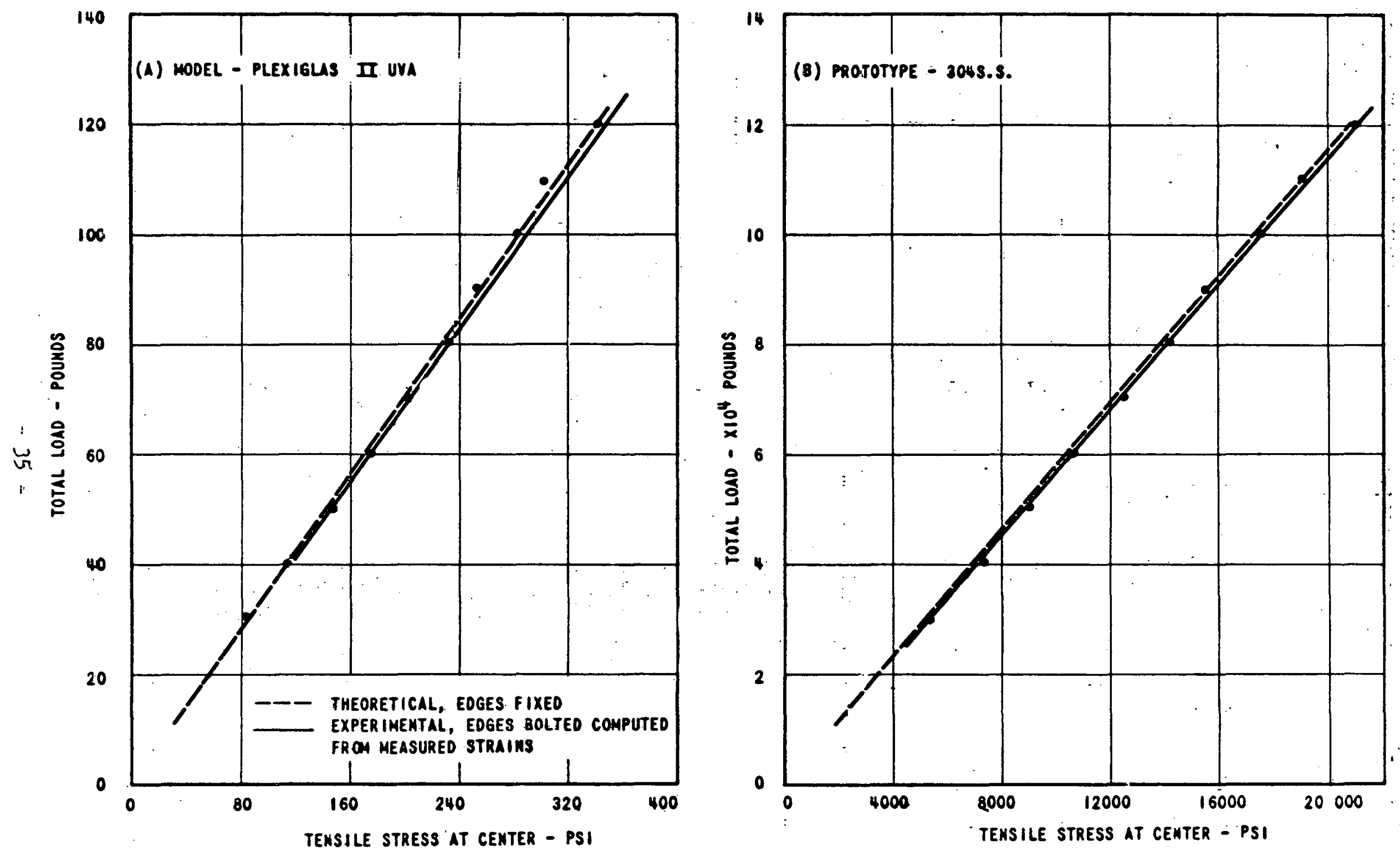

COMPARISON OF EXPERIMENTAL AMD - THEORETICAL TENSILE STRESS AT CENTER OF CIRCULAR PLATE UHDER COHCENTRIC UHIFORIILY DISTRIBUTED LOAD OF RADIUS $r_{0}$ 
bolted support edge theoretically as a built-in edge, their agreements are within 5\%, which is considered very" satisfactory for general engineering purposes.

Central deflections of various plate models under 76 individual loads were plotted against the total load as shown in Figure 14. The actual plate thicknesses of the various test models are different from each other. For comparison purposes, their observed deflections were all converted into equivalent values of a plate thickness of 0.375 inch. Deflection of all plate specimens under individual concentrated loading was approximately 17\% greater than that under the same total loading of unifurm concentric load.

Figures 4, 5, 6, 15,16 and 17 show the formation of the final cracking patterns in various perforated plate models as a result of the Stresscoat test. Due to the difficulties involved in providing a suitable temperature control during the Stresscoat drying period, temperature fluctuation of $\pm 9^{\circ} \mathrm{F}$ : was noted on the temperature recorder. Although the strain sensitivity of the coating was 0.0009 inch per inch as indicated by a calibration bar at, the time of the test, no attempt was made to obtain any quantitative conclusion from this test. However, the Stresscoat crack patterns provide a clear visual presentation of the regions of highest stresses, and indicated the direction of maximum principal stress.

Making direct comparisons of the slopes of the measured deflections and tensile stresses curves of the various perforated plate models, and that of the solid circular plate model under a uniformly concentric loading, the values of the deflection and ligament efficiencies were calculated. The results, from the average value of two different thicknesses of each type perforated plates, are given in Table 4 as follows:

Table 4

Experimental Values of Ligament and Deflection Efficiency for Various Perforated Plates

\begin{tabular}{|l|l|l|}
\hline Type of Circular Plate & $\mathrm{n}_{\mathrm{W}}$ & $\mathrm{n}_{\mathbf{S}}$ \\
\hline Plate perforated with circular holes & 0.461 & 0.517 \\
Plate perforated with cruciform openings & 0.683 & 0.825 \\
Plate perforated with circular holes & 0.306 & 0.442 \\
and cruciform openings & & 0.96 \\
\hline
\end{tabular}




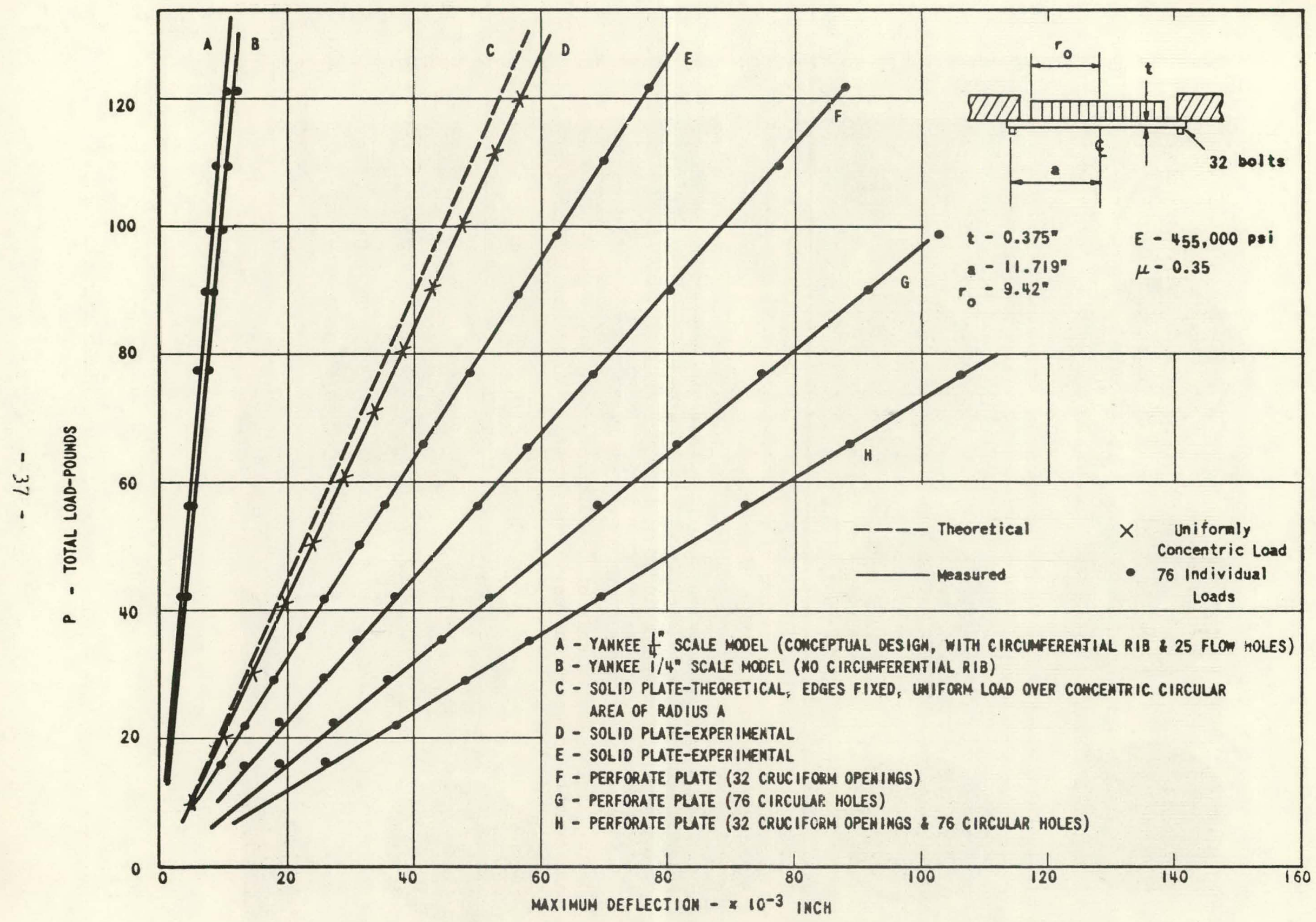

CENTER DEFLECTION VARIATION WITH LOAD FOR VARIOUS CIRCULAR PLATE MODELS

Figure 14 


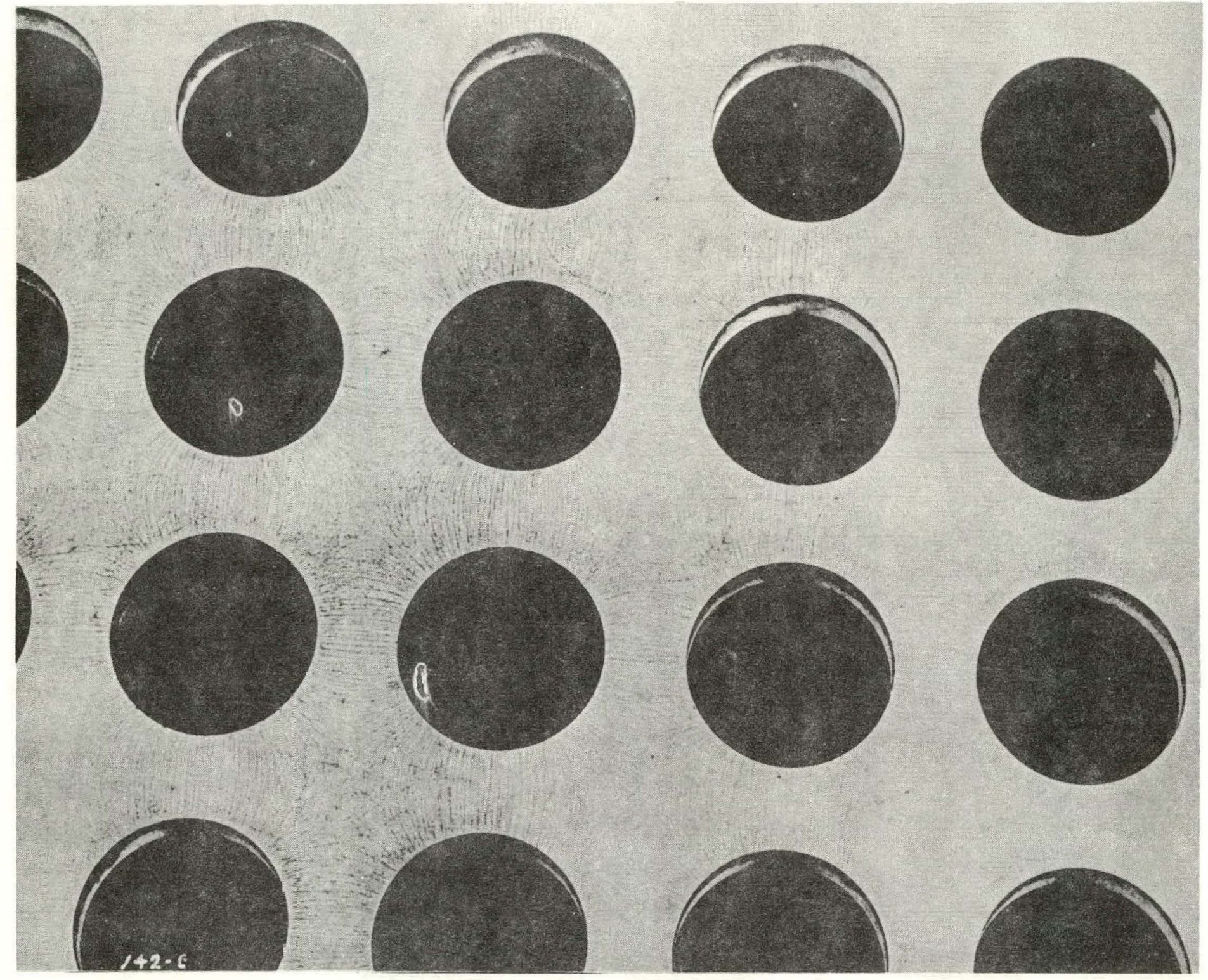

Fizure 15 - Enlarged View of Stresscoat Crack Pattern on Plate Model Perforated with Holes 


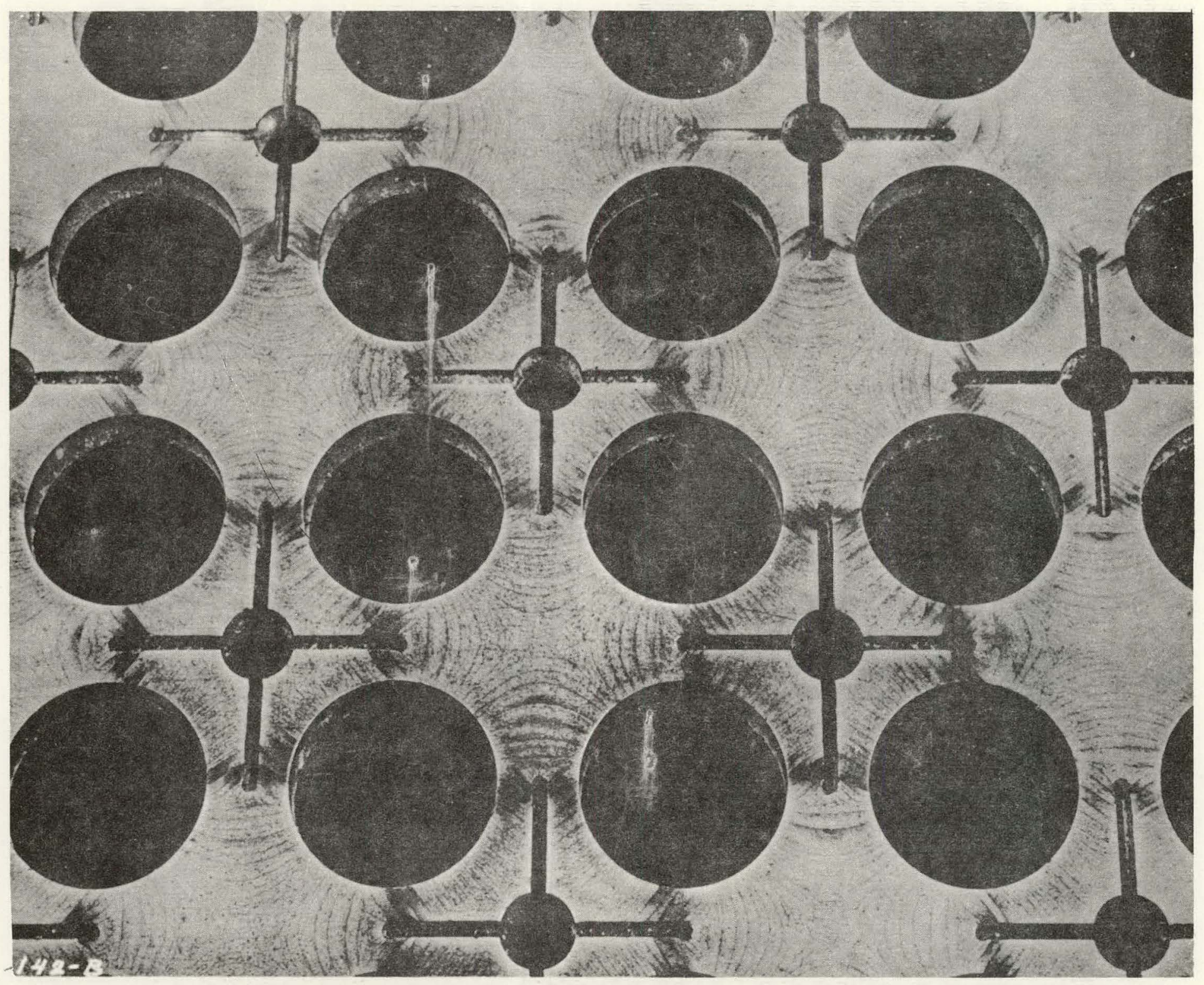

Figure 16 - Enlarged View of Stresscoat Crack Pattern on Plate Model Perforated with Holes and Cruciform Openings 


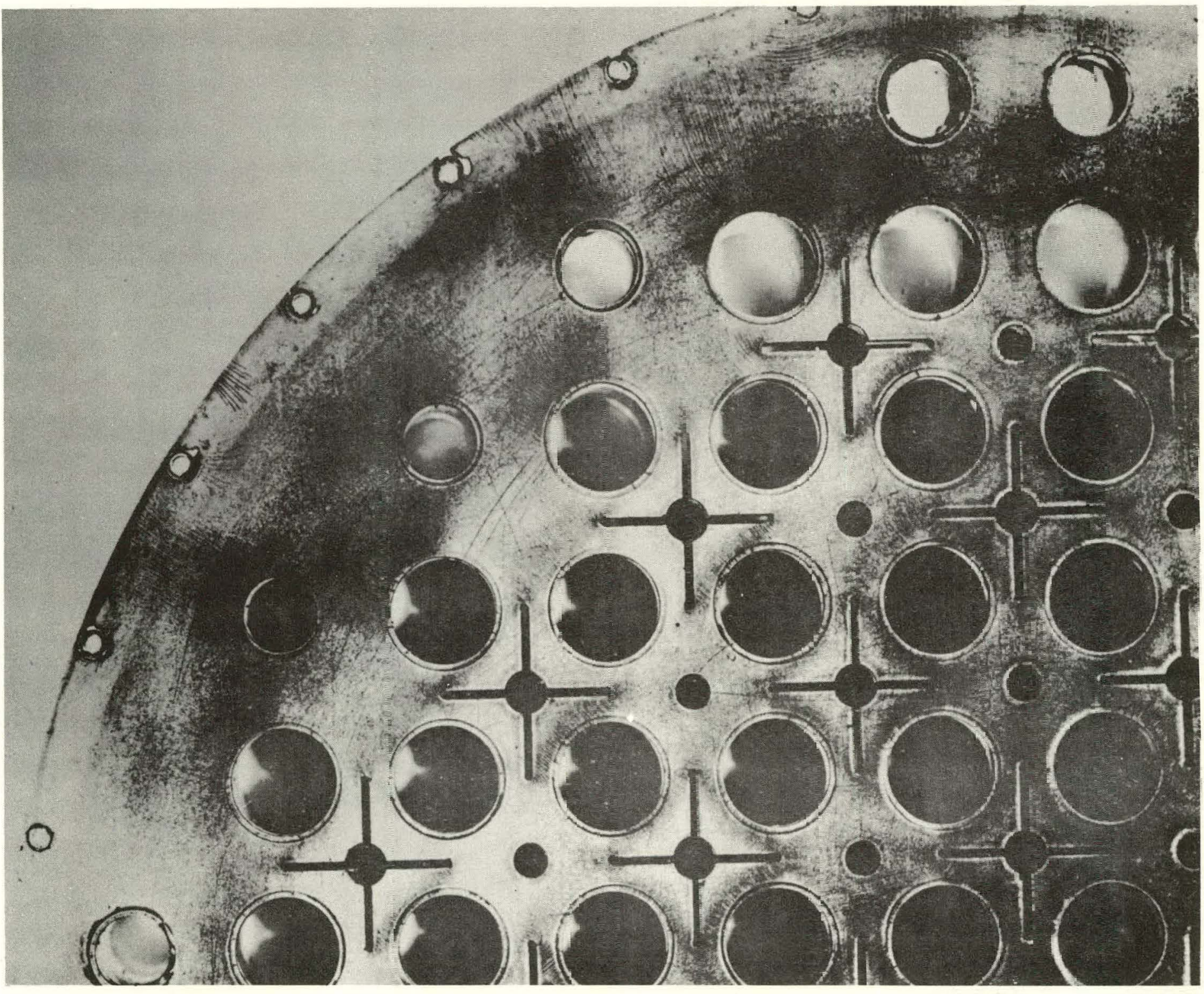

Figure 17 - Stresscoat Crack Pattern in a Quandrant of Yankee Core Support Structure Model 
Note that the total deflection or ligament efficiency of a plate perforated with holes and cruciform openings is approximately equal to the product of the two efficiencies obtained experimentally in each separate case.

Theoretical values of the deflection and ligament efficiencies of a plate perforated with holes were calculated with the proposed methods by aforesald investigators. No close agreement was found with the values obtained in this experiment. Tt is emphasized that there are inconsistencies existing among analytical approaches to the problem. Therefore, experimental confirmation is required to support theoretical analyses.

2. Sandwich Beam Specimen:

Central deflection of each sandwich beam specimen was measured and plotted against load, resulting in the establishing of a linear relationship. Figure 18 shows data for the load-deflection curves of four beam specimens (Nos. 1, 2, 3 and 4) having different overall heights, simply supported at the ends, and loads applied at two quarter-span points. Also, all beam specimens were tested with ten individual loads applied at the periphery of the circular holes, and were simply supported or bolted on the ends.

The slopes of the deflection-load curves were computed for each case and plotted against the height of the inserted spacers as shown in Figure 19. The data indicate that the beam with a cylindrical spacer height of $1.313^{\prime \prime}$ or an overall height of 2 inches, is the optimum height for design considerations, and that any additional increase in cylindrical spacer height will not increase the strength of the structure by a significant amount.

Figure 20. shows a comparison of test data of the four 2" overall height sandwich beam specimens (Nos. 3, 5, 6 and 7), with the variable parameters on beam thickness and spacer wall thickness. An increase in thickness of the bottom strip from $0.375 "$ to $0.417 "$ shows an increase in flexural stiffness of less than $4 \%$. No significant effect on the flexural stiffness is shown by increasing the wall thickness of the spacer from $0.125^{\prime \prime}$ to $0.250^{\prime \prime}$; however, a $5 \%$ decrease is indicated by reducing the wall thickness to 0.063 inch.

Specimen No. 3 was first tested over a span length of 23.438 inches and then cut into a shorter span of 11.49 inches, and tested in the same manner. Test results are shown by curves \#3 and \#3A in Figure 20 for the long and short span beams respectively, and were taken to determine the core-layer shear modulus $G_{c}$. Curve \#3B is the laad-deflection data of ecimen No. 3, simply supported and loaded at ten points, and was taken to compute the shear stiffness $\Omega_{\mathrm{gx}}$ of the sandwich structure. 


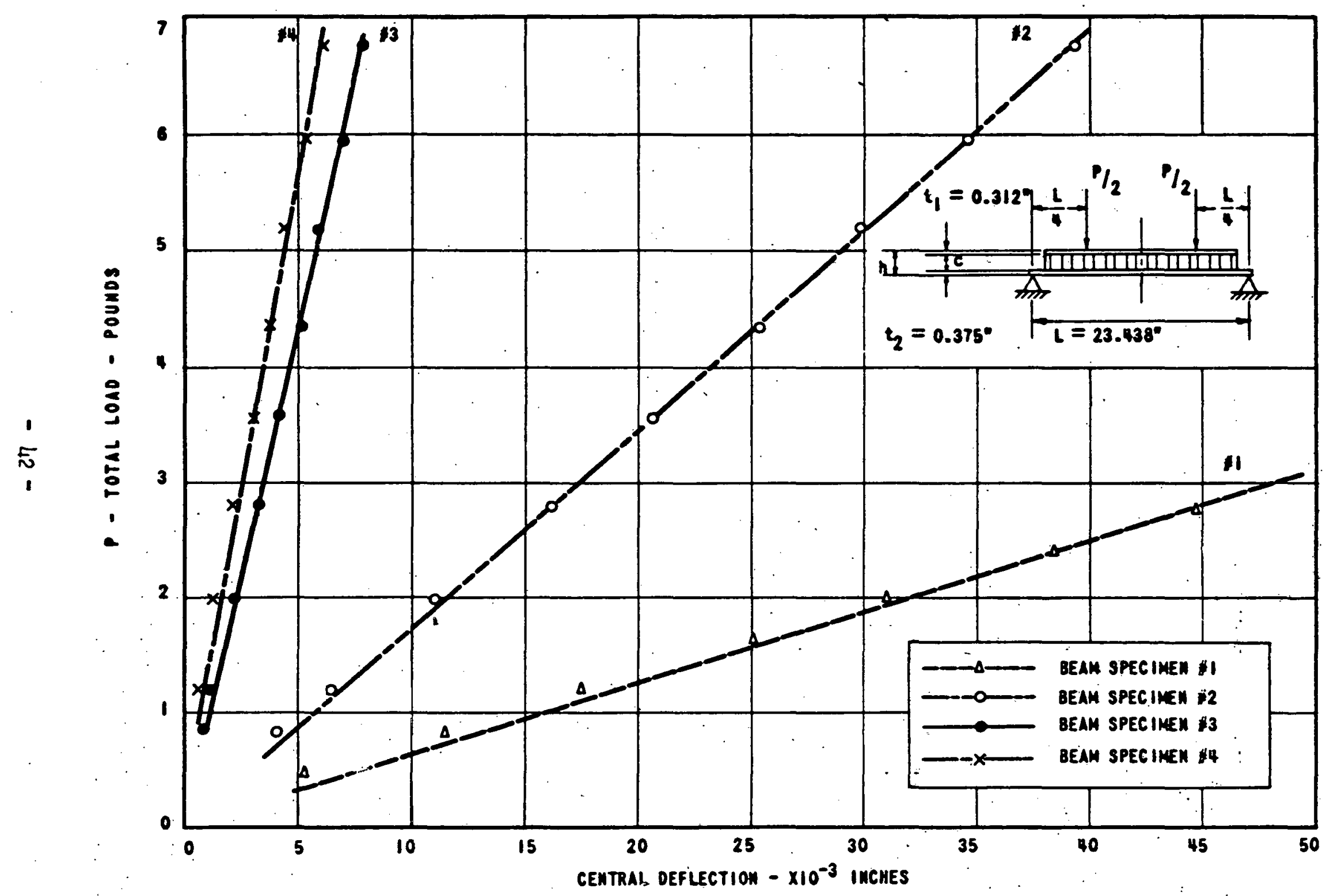

CENTRAL DEFLECTION VARIATION WITH LOAD APPLIED AT TNO QUARTER-SPAN POINTS AHD : SIMPLY SUPPORTED AT THE ENDS FOR VARIOUS SAHDWICH BEAH SPECIMEHS

Figure 18 


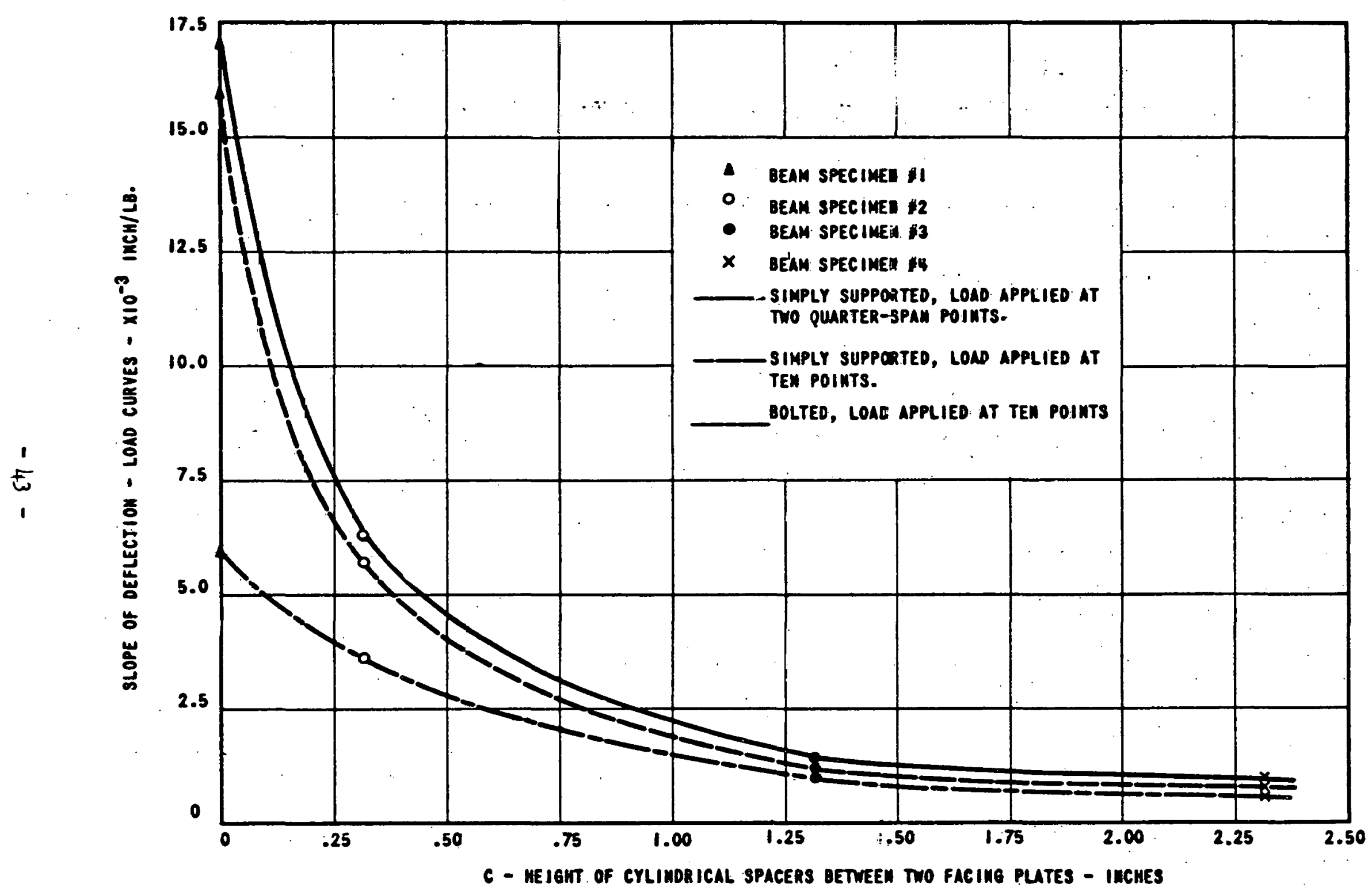

SLOPE OF DEFLECTION - LOAD CURYES VS HEIGHT OF CYLIMDRICAL SPACERS

Flgure 19 


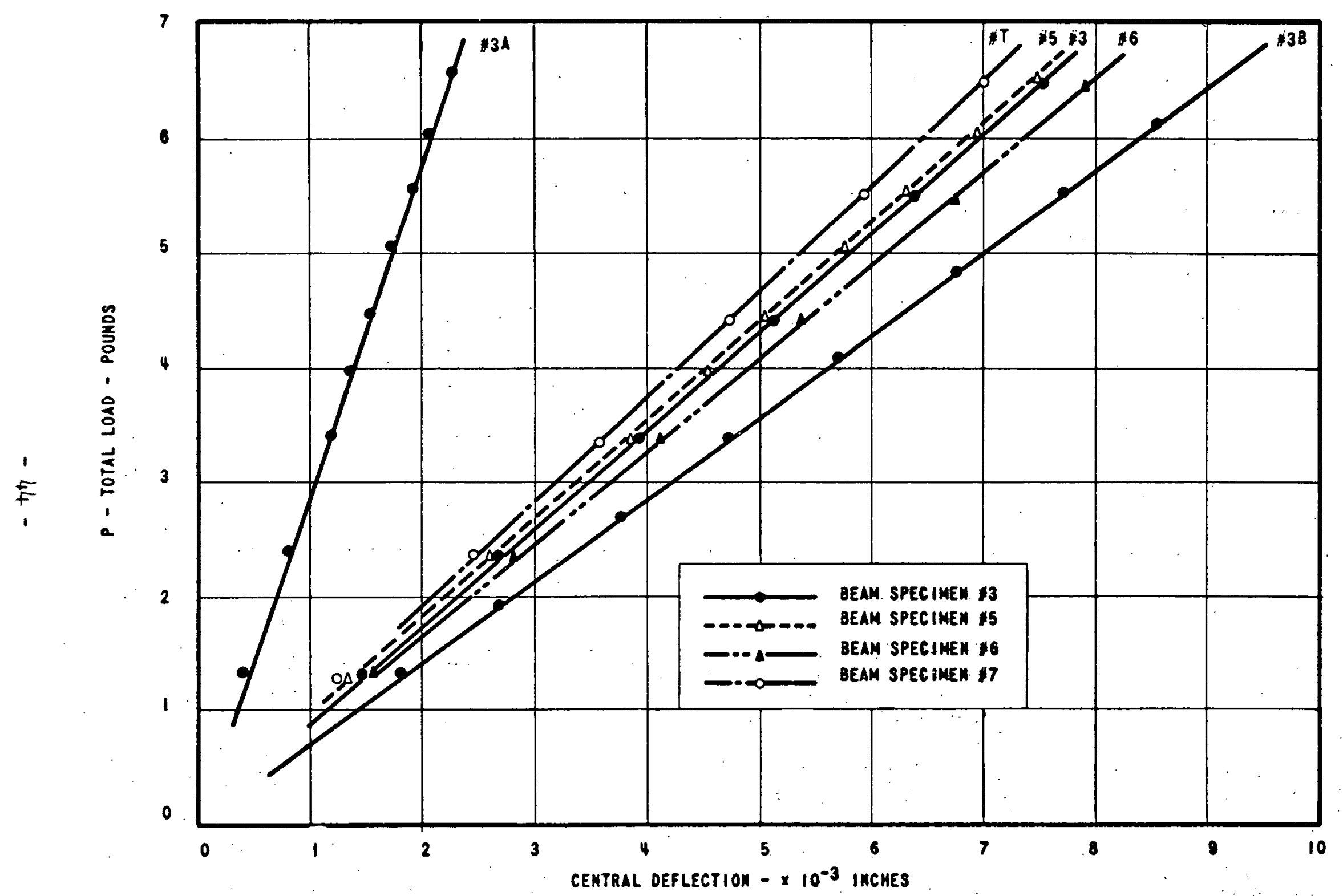

CENTRAL DEFLECTION VARIATIOH WITH LOAD APPLIED AT THO QUARTER-SPAN POINTS AHO SIMPLY

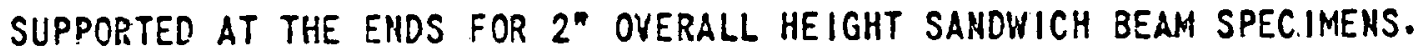

Figure 20 


\section{Yankee Core Support Structure Model:}

Using the data obtained from the optimization study of the sandwich beams, the Yankee core support structure model was then designed. T'he physical constants of this sandwich-type structure were also calculated by the simple beam deflection formulas and equations (6) and (7). The results are tabulated as follows:

Table 5

Experimental Values of the Physical Constants for the Yankees Core Support Structure

\begin{tabular}{|c|c|c|}
\hline Physical Constants & Model & $\begin{array}{c}\text { Reference } \\
\text { Design }\end{array}$ \\
\hline $\begin{array}{l}\text { Flexural Stiffness, lbs/in } \\
\text { a. } D, \text { (by Eq. 6) } \\
\text { b. } D_{x}=n_{w} D \\
\text { c. } D_{x} \text {, (specimen tests) } \\
\text { Shear Stiffness, Dqx, Ibs/in } \\
\text { Core-layer Shear Modulus, } G_{c}, \\
\quad \text { Ibs/in } 2\end{array}$ & $\begin{array}{r}24.20 \times 10^{4} \\
7.42 \times 10^{4} \\
8.50 \times 10^{4} \\
7.60 \times 10^{4} \\
\therefore 1.29 \times 10^{3}\end{array}$ & $\begin{array}{l}8.22 \times 10^{8} \\
2.54 \times 10^{8} \\
3.03 \times 10^{8} \\
2.71 \times 10^{8} \\
7.16 \times 104\end{array}$ \\
\hline
\end{tabular}

Figure 21 shows the measured deflections of the Yankee core support structure'model versus radius for various concentric uniformly distributed loads. Relative deflection measurements were made at more than thirty points, representing ten different radial locations on the bottom surface with reference to the point on the bolted circle. Smooth curves drawn through the average point of: three readings gave a good approximation to the bottom surface deflection curves.

Figure 22 shows the measured deflection and the computed slope curves of the Yankee core support structure model under a total load of 100 lbs. using 76 colums of steel washers simulating the fuel assemblies in the reactor. Taking the first differences of deflection at the adjacent points separated by a small radial distance, $\Delta r$, gave a close approximation to the slope variation on the bottom surface, $y^{\prime}=\Delta y / \Delta r$. The maximum deflection of the model was $0.0081^{\prime \prime}$, from which the corresponding maximum reference design deflection by equation $(8)$ is predicted to be, $y_{\max }=$ $0.0081 \times 4.5=0.0365 "$. The maximum slope at the bottom surface was $1.32 \times 10^{-3}$ inches per inch, and by equation (9) the corresponding maxdmum reference design slope is predicted to be $1.504 \times 10^{-3}$ inches per inch. 
Tests in the hydraulic loop indlcated that the size of the coolant water flow holes in the lower core support structure had a larger effect on the flow distribution in the core than did the internal geometry of the reactor core. It was recommended that the diameter of one water hole located at the center and four holes located $90^{\circ}$ apart at a 10.83 inch radial distance from the center be increased from 1.625 to 3.0 inches. The Yankee core support structure model was modified accordingly and tests indicated that this modification increased the deflection of the core structure by approximately 10\%. The maximum deflection and slope of the modified reference design are predicted to be 0.0415 inch and $1.71 \times 10^{-3}$ in/in respectively.

The rigidity of the Yankee core support structure model was decreased approximately 25\% without the circular reinforcing rib joining the two plates at the pertphery of the smaller diameter top plate as indicated by curves $A$ and $B$ in Figure 14.

Figures 23, 24, and 25 show the radial, tangential, and principal stresses, respectively, computed from the measured strains on the Yankee core support structure model. The locations of the numbered electrical resistance strain gages are presented in Figure 3, and are so arranged that one can obtain a comparative magnitude of the localized strain distribution in the core support structure. Gage numbers 14, 27 and 29 were mounted at the inner surface of three separate cylindrical spacers and they indicated a small compressive stress at the higher loading. Stresses on the outer surface of the circular reinforcing rib were measured vertically by gage No. 23 and circumferentially by gage No. 24, which are not shown in Tigure 3, but whose experimental results are given in Figures 23 and 24. Maximum radial stress is indicated by gage No. 5 located at the end of the crucif orm openings near the center, while the maximum tangential stress by gage No. 11B located at the outer ring of the core structure.

Strain gages measured the major and minor principal strains, oriented in the directions perpendicular and parallel to the stress trojectories as obtained from the stresscoat tests. Test results are given in Figure 25. Gage No. 19 which was placed at one side of the fuel assembly support spacer in. an outer row, registered the maximum stress of approximately $57 \mathrm{psi}$ at the design load. By equation (10) the stress on the reference design is computed to be $3600 \mathrm{psi}$. From the. strains measured by gage Nos. 3 and 7, the shear stress at the narrow region between the circular hole and the cruciform openings near the center of the core support structure was computed to be approximately 2500 psi. 


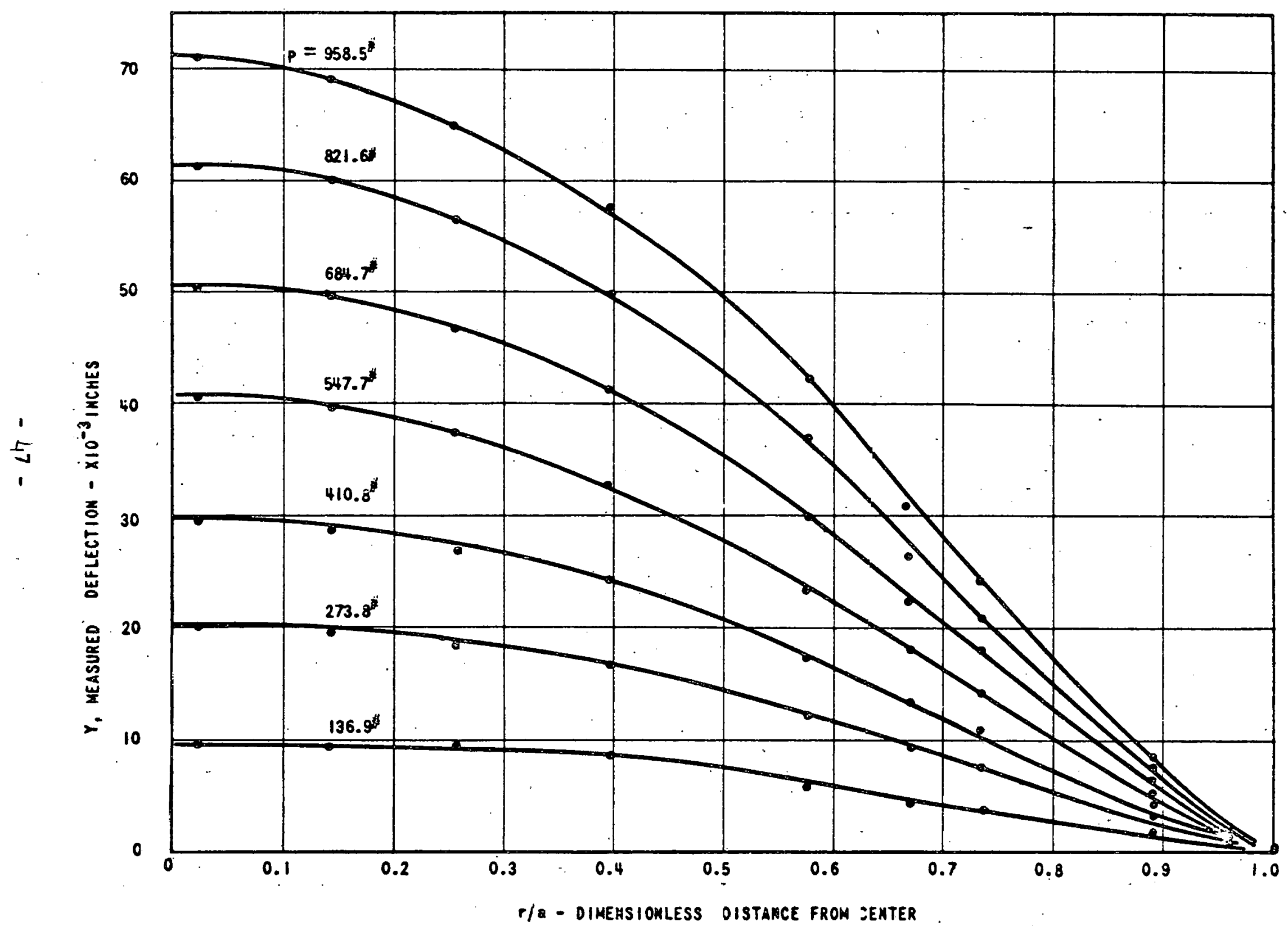

DEFLECTION YARIATION WITH RADIAL LOCATION FOR YANKEE CORE SUPPORT STRUCTURE MODEL UNDER UNIFORMLY CONCENTRIC LOAD.

Figure 21 


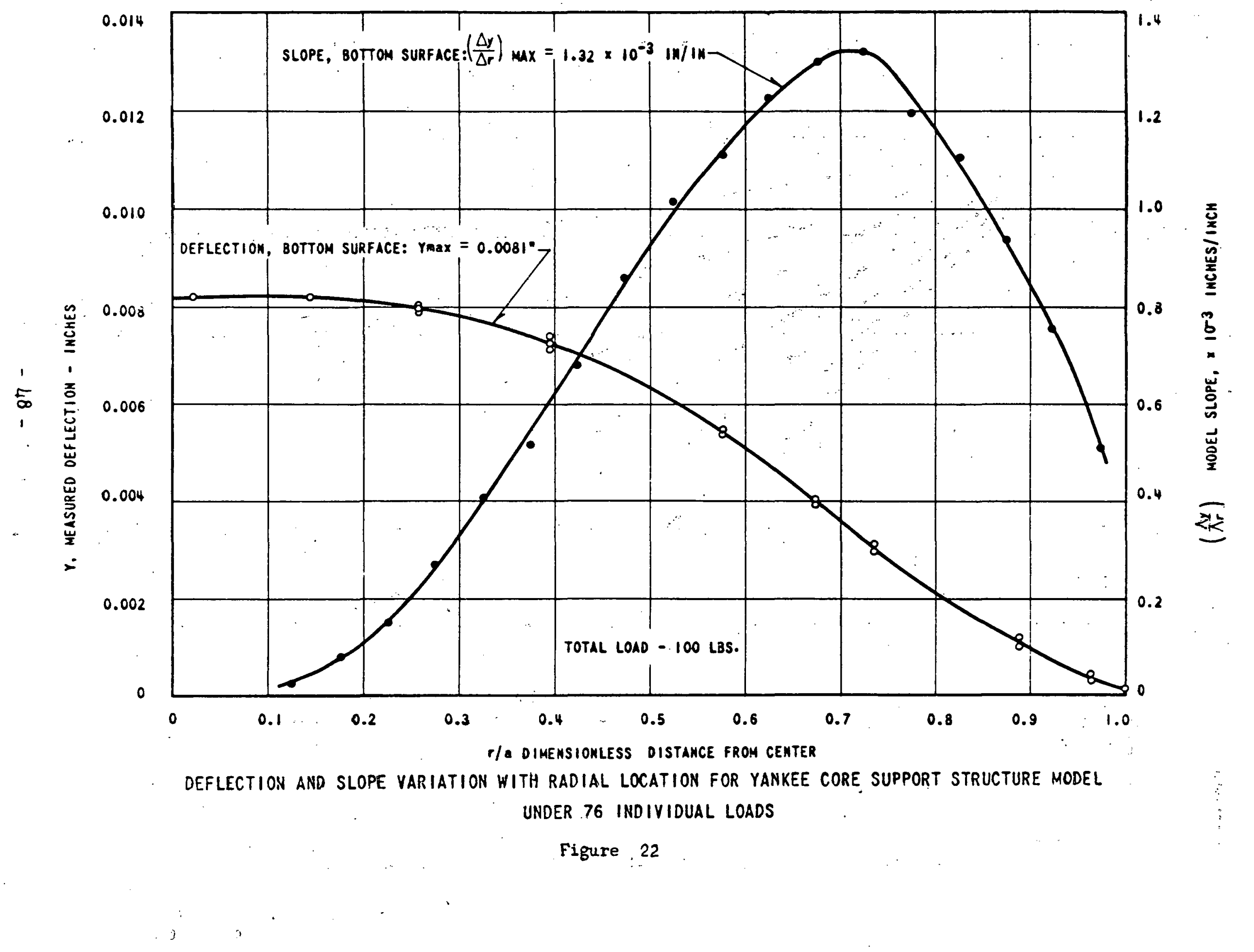




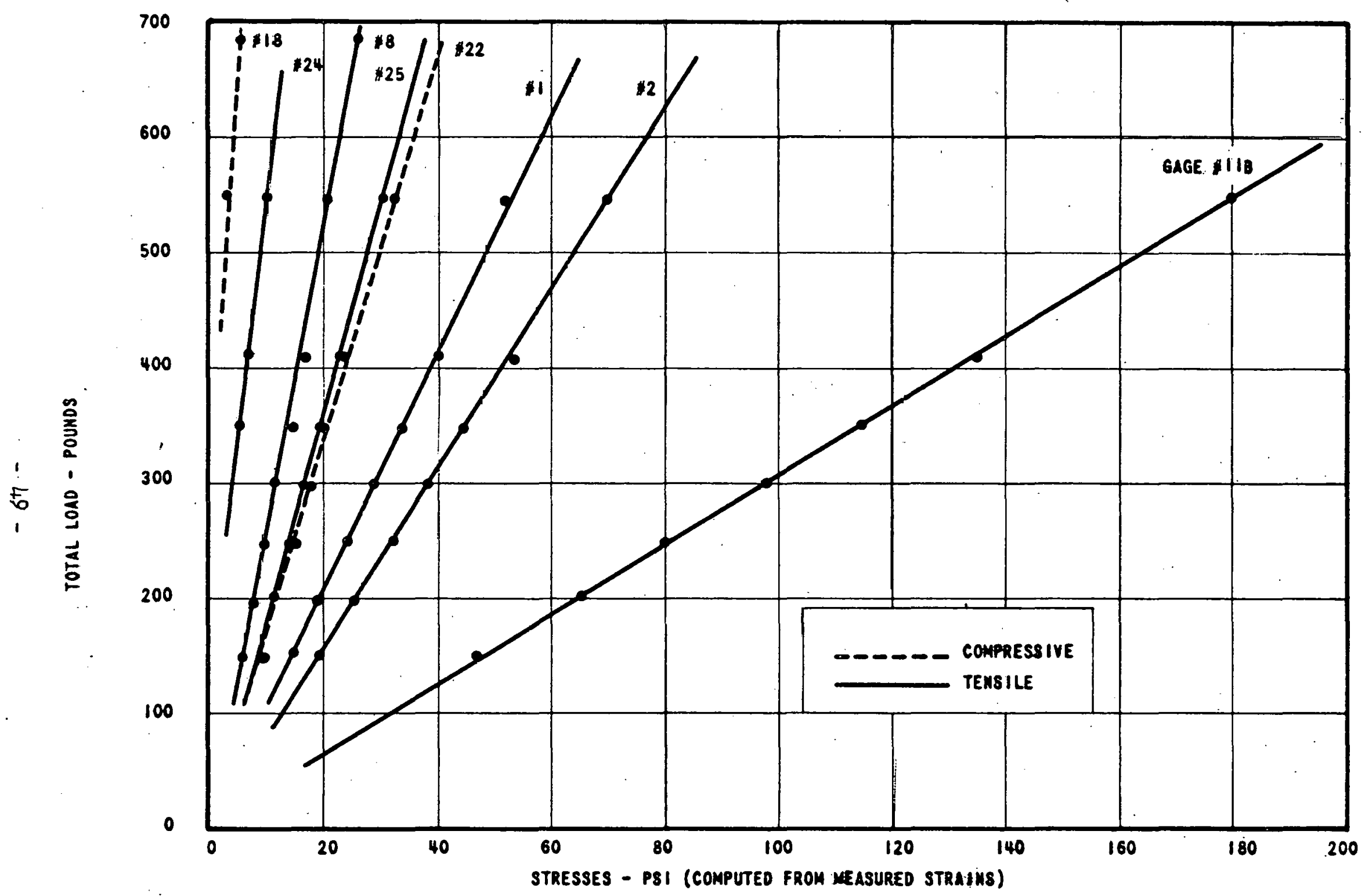

TANGENTIAI. STRESSES OH THE YANKEE CORE SUPPORT STRUCTURE MODEL

Figure 23 


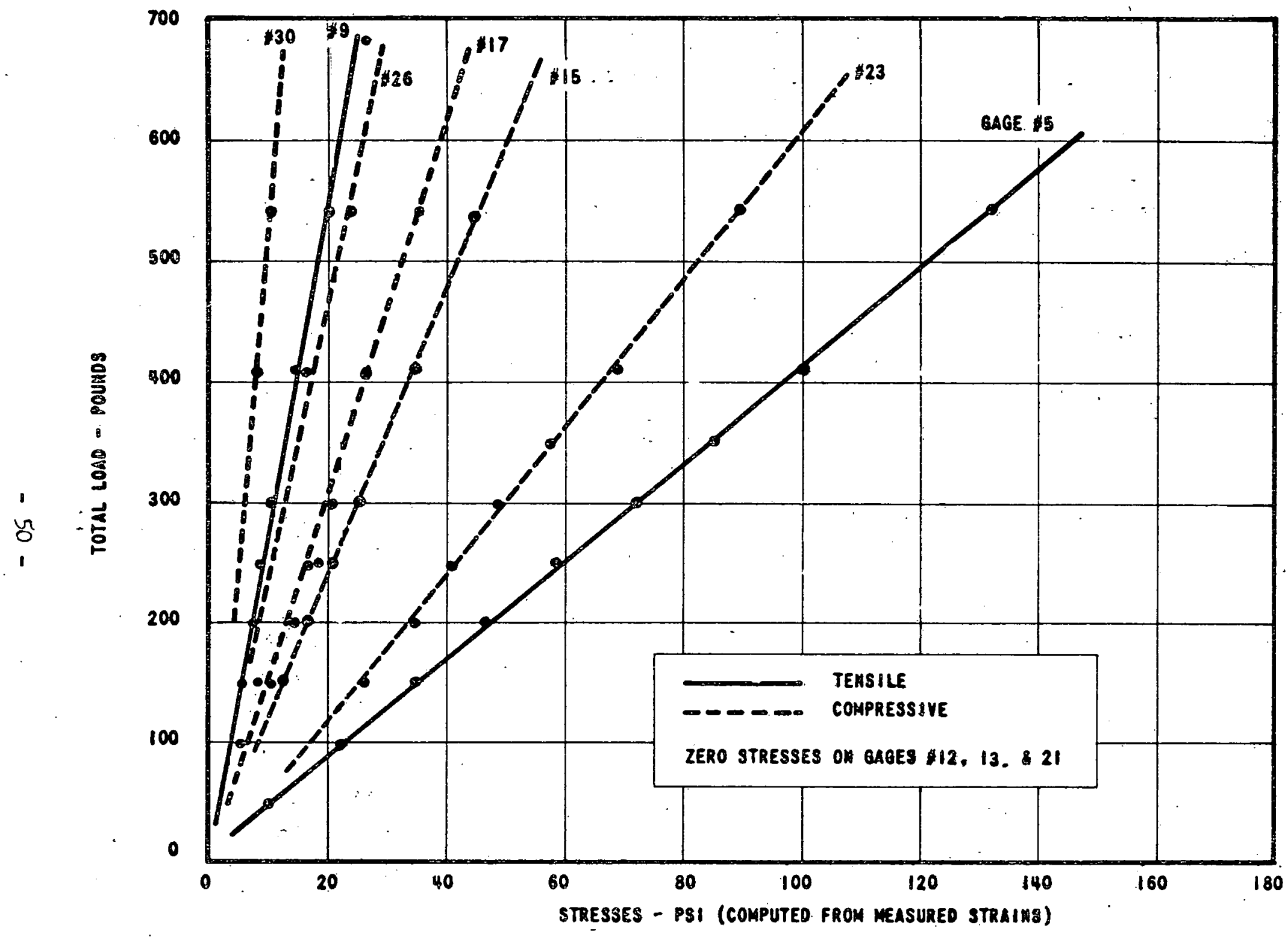

RADIAL STRESSES ON THE YANKEE CORE SUPPORT STPUCTURE MOOEL 


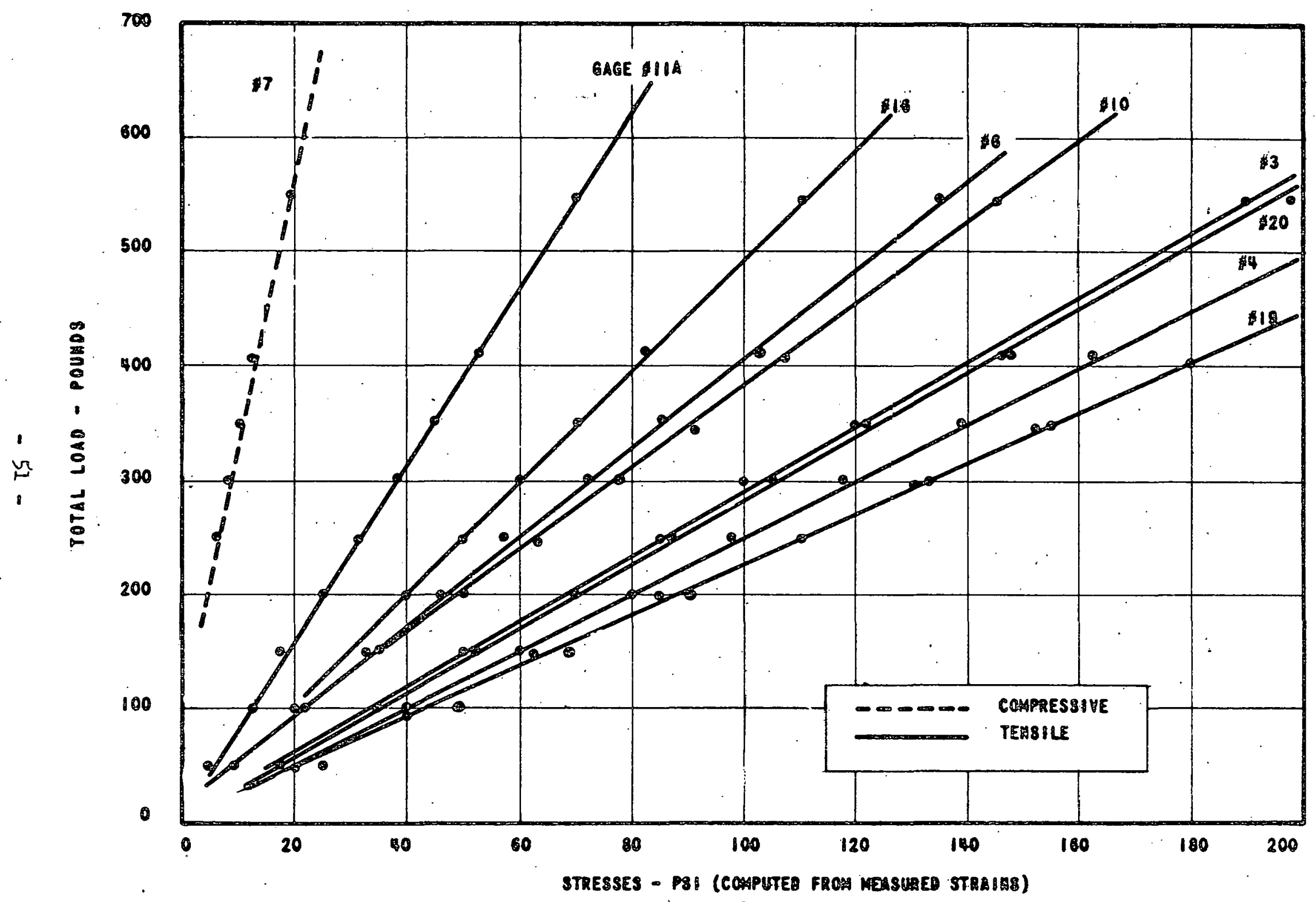

PRIHCIPAL STRESSES OH THE YAMKEE CORE SUP FORT STRUCTURE MOOEL

Figure 25 
VII. BIBLIOGRAPHY

1. Gardner, K. A.

2. Gardner, K. A.

3. Miller, K. A. G.

4. Duncan, J. P.

5. Malkin, I.

6. Horvay, $G$.

7. Horvay, G.

8. Horvay, G.

9. Yu, Y. Y.

10. ASTM, No. 118

11. Reissner, E.

12. Reissner, E.

13. Reissner, E.

14. Iibove, $C$. Batdorf, S. B.
- "Heat Exchanger Tube-Sheet Design", Journal of Applied Mechanics, Trans. ASME, Vol. 70, 1948, pp. 377-385.

- "Heat Exchanger Tube-Sheet Design 2 - Fixed Tube Sheets", Journal of Applied Mechanics, Trans. ASME, Vol. 76, 1952, pp. 159-166.

- "The Design of Tube Plates in Heat Exchangers", Proc. of I. Mech. Engr., London, England,' Serles B, Vol. 1, 1952. pp. 215-231.

- "The Structual Efficiency of Tubo Plates for Heat Exchangers", Proc of I. Mech. Engr., Iondon, England, No. 39; Vol. 169, 1955, pp. 789-810.

- "Notes on a Theoretical Basis for Design of TubeSheets of Triangular Layout", Trans. ASME, Vol. 74, 1952, pp. 387-396.

- "Thermal Stresses in Perforated Plates", Proc. of the 1st. U.S. National Congress of Applied Mechanics, 1951, pp. 247.

- "Bending of Honeycombs and of Perforated Plates", J. Applied Mechanics, Vol. 19, No. 1, 1952, pp. 122.

- "The Plane Stress Problem of Perforated Plates"; J. Applied Mechanics, Vol. 19, No. 3, 1952, pp. 355-360.

- "Rational Analysis of Heat-Echanger Tube-Sheet Stresses", J. Applied Mechanics, Trans. ASME, Vol. 78, 1956, pp. $468-473$.

- "Symposium on Structural Sandwich Constructions", Special Technical Publication, June, 1951.

- "The Effect of Transverse Shear Deformation on the Bending of Elastic Plate"; J. Applied Mech. Vol. 12, June, 1945, pp. A-69.

- "Finite Deflections of Sandwich Plates", J. Aero. Sc1. Vol. 15, July, 1948, pp. 435-440.

- "Small Bending and Stretching of Sandwich-Type Shells", NACA, Rept. \#975- 1950.

- "A General Small-Deflection Theory for Flat Sandwich Plates", NACA, Rept.\# 899, 1948. 
15. Hoff, N, J. Mautner, S. E.

16. March, H. W.

17. Ericksen, W. S. March, H. W.

18. March, H. W. Smith, C. B.

19. Stein, M. Mayers, J.

20. Anderson, M. S. Updegrafr, R.

21. Kommers, W. J.

22. Kuenzi, E. W. Ericksen, W. S.

23. Werren, F. Norris, C. B.

24. Ringelstetter, I. Voss, A. W. Warris, C. B.

25. Military Standard

26. Murphy, G.

27. Langnaar, H. I.

28. Hetenyi, M.

29. Leven, M. M.

30. Roark, R. J.

31. Timoshenko, S.
- "Bending and Buckling of Sandwich Beam", Journal of " the Aero. Sci. Vol. 15, December, 1948, pp. 707-720.

- "The Effects of Shear Deformation in the Core of a Flat Rectangular Sandwich Panel", U.S. Forest Products Laboratory, Rept. \# 1583, 1948.

- "Deflection Under Uniform Load of Sandwich Panels Having Facings of Unequal Thickness", U.S. FPI Rept. \# 1583-C, 1950。

- "Flexural Rigidity of a Rectangular Strip of Sandwich Construction", U. S. FPL Rept. \# 1505, Revised 1955.

- "A Small-Deflection Theory for Curved Sandwich Plates", NACA Rept. \# 1008, 1950.

- "Some Research Results on Sandwich Structure", NACA Tech. Note lim9, June, 1957.

- "Strength Properties of Plastic Honeycomb Core Materials", U.S. FPL Rept. No. 1805.

- "Shear Stability of Flat. Panels of Sandwich Construction", FPL Rept. \# 1560, March, 1951.

- "Analysis of Shear Strength of Honeycomb Cores for Sandwich Constructions", NACA, Tech. Note 2208; Oct. 1950.

- "Effect of Cell Shape on Compressive Strength of Hexagonal Honeycomb Structures", NACA Tech. Note 2243, December 1950.

- "Sandwich Constructions and Core Materials; General Test Methods", MII-STD-LOIA, June, 1956.

- "Similitude in Engineering", Ronald Press Co., New York.

- "Dimensional Analysis and Theory of Models", John Wiley \& Sons, Inc., New York, 1950.

- "Handbook of Experimental Stress Analysis", John Wiley \& Sons, Inc., New York, 1956.

- "Deflections and Nozzle Inclinations of ATW Core I Heat From Plastic Model", Westinghouse Research Memo 405 F.F. 161-MI, November, 1957.

- "Formulas for Stress and Strain", McGraw-Hill Book Co. New York, 1954.

- "Theory of Plates and Shells", McGraw-Hill Book Co. New York, 1940. 